\title{
O IDOSO, A CIDADE E A APO: UMA RELAÇÃO ENTRE PERCEPÇÃO E APROPRIAÇÃO
}

\author{
GUIMARÃES, Elisa Santos \\ PROGRAU - UFPEL, e-mail: elisaguima@gmail.com \\ MEDVEDOVSKI, Nirce Saffer \\ PROGRAU - UFPEL, e-mail: nirce.sul@gmail.com \\ SOPEÑA, Sirlene de Mello \\ FAURB - UFPEL, e-mail: sirmellos@hotmail.com
}

\begin{abstract}
RESUMO
Esta pesquisa finalizada de mestrado suscita reflexões quanto à percepção do ambiente construído pelos idosos e à maneira como dele se apropriam. A motivação surgiu da necessidade de adequação das cidades frente ao envelhecimento populacional. Logo, o problema central refere-se à criação de cidades planejadas a partir da percepção e do comportamento dos idosos. O estudo fundamentou-se na área da Arquitetura e Urbanismo, com interfaces na Percepção e Gerontologia Ambiental. Através de instrumentos de APO, explicitou-se uma relação ambiente-comportamento que visou agregar conhecimento às demais iniciativas que compõe a rede mundial de desenvolvimento de cidades amigas do idoso. A pesquisa foi conduzida a partir do estudo de caso aplicado em Pelotas, nos bairros Centro, Fragata e São Gonçalo. Os resultados indicaram que no Centro, onde há a melhor qualidade do espaço urbano, há a maior apropriação representada pela quantidade de idosos nas áreas de estudo; e no São Gonçalo, onde a qualidade do espaço foi identificada como a pior, há a menor apropriação. Concluiu-se que os resultados apresentados apontam para a influência que a qualidade do espaço construído exerce sobre o modo como os idosos o percebem e a defluência desta percepção na maneira como deste local se apropriam.
\end{abstract}

Palavras-chave: Percepção, Apropriação, Cidade amiga do idoso.

\begin{abstract}
This completed master's research raises questions about the perception of the environment built by the elderly and how they appropriate it. The motivation arose from the need to adapt the cities to the aging population. Therefore, the central problem is the creation of cities that are planned based on the perception and behavior of the elderly. The study was based on the area of Architecture and Urbanism, with interfaces in Environmental Perception and Gerontology. Through APO instruments, an environment-behavior relationship was explained that aimed to add knowledge to the other initiatives that make up the global network of city-friendly elderly development. The research was conducted from the case study applied in Pelotas, in the districts Centro, Fragata and São Gonçalo. The results indicated that in the Center, where there is the best quality of urban space, there is the greater appropriation represented by the number of elderly in the study areas; and in São Gonçalo, where the quality of space was identified as the worst, there is less appropriation. It was concluded that the presented results point to the influence that the quality of the built space exerts on the way the elderly perceive it and the defluence of this perception in the way of this place they appropriate.
\end{abstract}

Keywords: Perception, Appropriation, Elderly friendly cities.

GUIMARÃES, E. S.; MEDVEDOVSKI, N. S.; SOPEÑA, S. M. O idoso, a cidade e a APO: uma relação entre percepção e apropriação. In: SIMPÓSIO BRASILEIRO DE QUALIDADE DO PROJETO NO AMBIENTE CONSTRUíDO, 6., 2019, Uberlândia. Anais... Uberlândia: PPGAU/FAUeD/UFU, 2019. p. 1273-1292. DOI https://doi.org/10.14393/sbqp19116. 


\section{INTRODUÇÃO}

Ao observar o contexto global, constata-se a necessidade de adequação das cidades frente ao envelhecimento populacional: processo que torna crescente a fração de pessoas idosas que usufruem do ambiente construído. A Organização Mundial da Saúde (OMS) promove ações que oportunizem o envelhecimento ativo: onde o acesso à saúde, participação e segurança é assegurado ao idoso. Assim, o envelhecimento populacional destaca-se como importante área de estudos para uma gestão urbana qualificada (ONU, 2002; OMS, 2008; SATIRO, 2014).

Portanto, o problema central concerne à criação de cidades democráticas, planejadas a partir da percepção e do comportamento dos usuários, com o designo de proporcionar cidades que acolham amigavelmente as pessoas idosas. Este estudo fundamentou-se na área da Arquitetura e do Urbanismo, desenvolvida no Programa de Pós-Graduação em Arquitetura e Urbanismo (PROGRAU) da Universidade Federal de Pelotas (UFPel), durante a elaboração da dissertação de mestrado de Guimarães (2018).

Adequar o ambiente para que seja amigável ao idoso está vinculado aos propósitos da Gerontologia Ambiental (GA), onde publicações demonstram o interesse na requalificação espacial em proveito das relações entre o idoso e cenário no qual está inserido. Assim, a GA aborda o espaço porque este incita - debate sobre o lugar do envelhecimento que recorrentemente relega $O$ indivíduo à situação de vulnerabilidade social (SATIRO, 2014).

O estudo da Percepção fundamentou-se em pesquisas da Psicologia Ambiental (PA) quando, na década de 60 do século XX, precursores visaram desenvolver métodos que captassem as relações ambiente-comportamento. O desenvolvimento desta análise perceptiva foi embasado no estudo realizado por Lynch, onde apresentou a metodologia dos Mapas Mentais (LYNCH, 1999).

Objetivou-se refletir sobre às particularidades apresentadas pelo público idoso em sua relação de percepção e apropriação do ambiente construído com o intuito de colaborar para a construção de cidades amiga do idoso.

A pesquisa foi conduzida a partir do estudo de caso aplicado em Pelotas, Rio Grande do Sul, e delimitou-se em recortes urbanos. Definiram-se recortes situados nos bairros $\left(1^{\circ}\right)$ Centro, $\left(2^{\circ}\right)$ Fragata e $\left(3^{\circ}\right)$ São Gonçalo.

O interesse ao tema surgiu pela participação nos debates do grupo de pesquisa "Place-Making with Older People: Towards Age Friendly Communities'" no Núcleo de Pesquisa em Arquitetura e Urbanismo (NAUrb), da Faculdade de Arquitetura e Urbanismo (FAUrb/UFPel), da qual pertencem as autoras deste artigo.

Compreende-se que este estudo corrobora sua relevância à comunidade acadêmica através da contribuição de análises e reflexões. Somado às demais pesquisas relativas à percepção e apropriação do idoso em relação às áreas urbanizadas, progridem rumo à conceituação de políticas públicas capazes de impulsionar o progresso de cidades amigas do idoso.

\footnotetext{
1 Financiada pelo Fundo Newton e ESRC, é uma parceria entre a Universidade Heriot-Watt, em Edimburgo, Reino Unido, com a UFPel, em Pelotas, Brasil, sob a coordenação do Dr. Ryan Woolrych e Dra. Adriana Portella.
} 


\section{FUNDAMENTAÇÃO}

\subsection{Envelhecimento Populacional}

Até o século $X X$, os idosos representavam uma pequena parcela da população global. Entretanto, avanços na área da saúde aumentaram a expectativa de vida e promoveram a queda das taxas de natalidade. Estimase que a população idosa global dobrará entre os anos de 2006 e 2050 - de $11 \%$ para $22 \%$ do total de habitantes - quando, ineditamente, o número de idosos será superior ao de crianças com até 14 anos de idade (ONU, 2002; OMS, 2008; IBGE, 2010). Em 2025, espera-se que a parcela pós-sexagenária brasileira atinja 32 milhões de idosos, 14\% dos habitantes, elencando o Brasil como sexto país com maior contingente idoso (AMARO; JOHANN; MEIRA, 2007; CUNHA et al., 2012).

Segundo o Instituto Brasileiro de Geografia e Estatística, a população idosa do Rio Grande do Sul duplicou neste século, atingindo 1,30 milhões de indivíduos em 2017 (11,53\% da população) e elencando o estado como o quarto maior em população pós-sexagenária. Em 2010, Pelotas apresentava 46 mil idosos, 14\% da população, porcentagem superior àquela estadual (IBGE, 2010).

Tais dados despertam preocupação quanto às consequências do envelhecimento da sociedade, tão carente de cenários que acolham de forma ativa, independente e saudável seu idosos (CUNHA et al., 2012; GONZÁLEZ; TOPETE, 2016).

\subsection{Percepção e Apropriação}

A contar da década de 60, a vida pública despertou o interesse de pesquisadores como Robert Sommer, Kevin Lynch, Gordon Cullen e Oscar Newman (GEHL; SVARRE, 2013). Lynch (1999) destacou-se ao apontar os atributos da cidade legível através de mapas mentais quando analisou as imagens que moradores de três cidades norte americanas mantinham das áreas onde residiam.

A percepção é compreendida como a soma da memória das experiências vividas com informações processadas no instante em que o usuário interage com o ambiente. Ao ser um produto da percepção, as imagens mentais são analisadas quanto a sua identidade, estrutura e significado. Lynch alega existir um consenso nas imagens dos integrantes de uma coletividade porque as cidades proporcionam significados que tendem a ser compartilhados pelos indivíduos que possuem experiências em um mesmo cenário (LYNCH, 1999).

Compreende-se apropriação como manifestações propositais ou inconscientes entre os indivíduos e o ambiente (DUPLAY; DUPLAY, 1985; MEDVEDOVSKI, 1998) e "está ligada à vivência do local (...) pelo modo como o ambiente responde aos anseios dos usuários" (CAVALCANTI, 2011 , p. 73).

Acrescenta-se que a construção do espaço é o fruto da imposição de forças hegemônicas somadas à apropriação. Ao considerar que razões políticas e culturais influenciam na apropriação, admite-se que os projetos devem ir além de preocupações como forma porque esta não assegura que no local surgirão as formas de apropriação para o qual se destina (DUVAL, 1997). 


\subsection{Variáveis e indicadores}

A determinação de variáveis e indicadores viabiliza a análise de questões perceptivas e de apropriação.

Variáveis centradas no usuário:

- Legibilidade: garante aos usuários familiaridade, ao reconhecer bairros, limites e vias, e memorizar tais informações (LYNCH, 1999).

- Segurança: influencia na vontade de frequentar os espaços e revela fatores ambientais e psicológicos (OMS, 2008).

- Acessibilidade: visa o deslocamento independente e seguro dos idosos (GRINOVER, 2006).

- Conforto: relacionado à maneira com que a estrutura se harmoniza com as pessoas (GEHL, 2013).

- Atratividade: reforçada através do uso, qualificação e manutenção dos espaços de transição (GEHL, 2013).

- Adequação visual: refere-se ao empenho de combinar soluções até que se atinja a expressão visual desejada (BENTLEY et al., 2005).

Indicadores centrados no ambiente:

- Equipamentos e infra-estruturas de apoio: mobiliário urbano (OMS, 2008).

- Equipamentos para acessibilidade: relacionamos à mobilidade do pedestre nos espaços públicos (AMOR, 2011).

- Equipamentos de trânsito: onde a imagem do pedestre é respeitada em relação aos veículos (OMS, 2008).

- Locais de consumo e bens de serviços urbanos: pontos comerciais e de serviços (NETTO; KRAFTA, 1999).

- Locais distribuidores de fluxo social: embarque/desembarque de pessoas ao transporte público (NETTO; KRAFTA, 1999).

- Locais de lazer e prática de atividades físicas: destinados às atividades cotidianas sociais e esportivas (GEHL, 2013).

- Elementos naturais: como árvores e canais hídricos (OMS, 2008).

- Limpeza urbana: acúmulo de lixo e presença de lixeiras (OMS, 2008).

\section{METODOLOGIA}

Definiu-se como o objeto estudo de caso o município de Pelotas, Rio Grande do Sul. Os critérios de definição dos recortes (extratos da totalidade urbana) foram a alta concentração de idosos e apontar diferentes realidades financeiras. Em Pelotas há: de 0 a 38,18 idosos/hectare e de 0 a R\$14.234,89/mensais por domicílio (IBGE, 2010). Tem-se como:

- $1^{\circ}$ recorte, no Centro: alta concentração de idosos $(2,91$ a 21,68 idosos/ha) e renda mensal de $\mathrm{R} \$ 3.624,57$ a $\mathrm{R} \$ 8.586,57$-maior poder aquisitivo (IBGE, 2010). 
- $2^{\circ}$ recorte, no Fragata: alta concentração de idosos (2,91 a 11,20 idosos/ha) e renda mensal de zero a $R \$ 3.624,56$ - poder aquisitivo intermediário (IBGE, 2010).

- $3^{\circ}$ recorte, no São Gonçalo: alta concentração de idosos $(2,91$ a 11,20 idosos/ha) e renda mensal de zero a $R \$ 2.188,00$ - menor poder aquisitivo (IBGE, 2010).

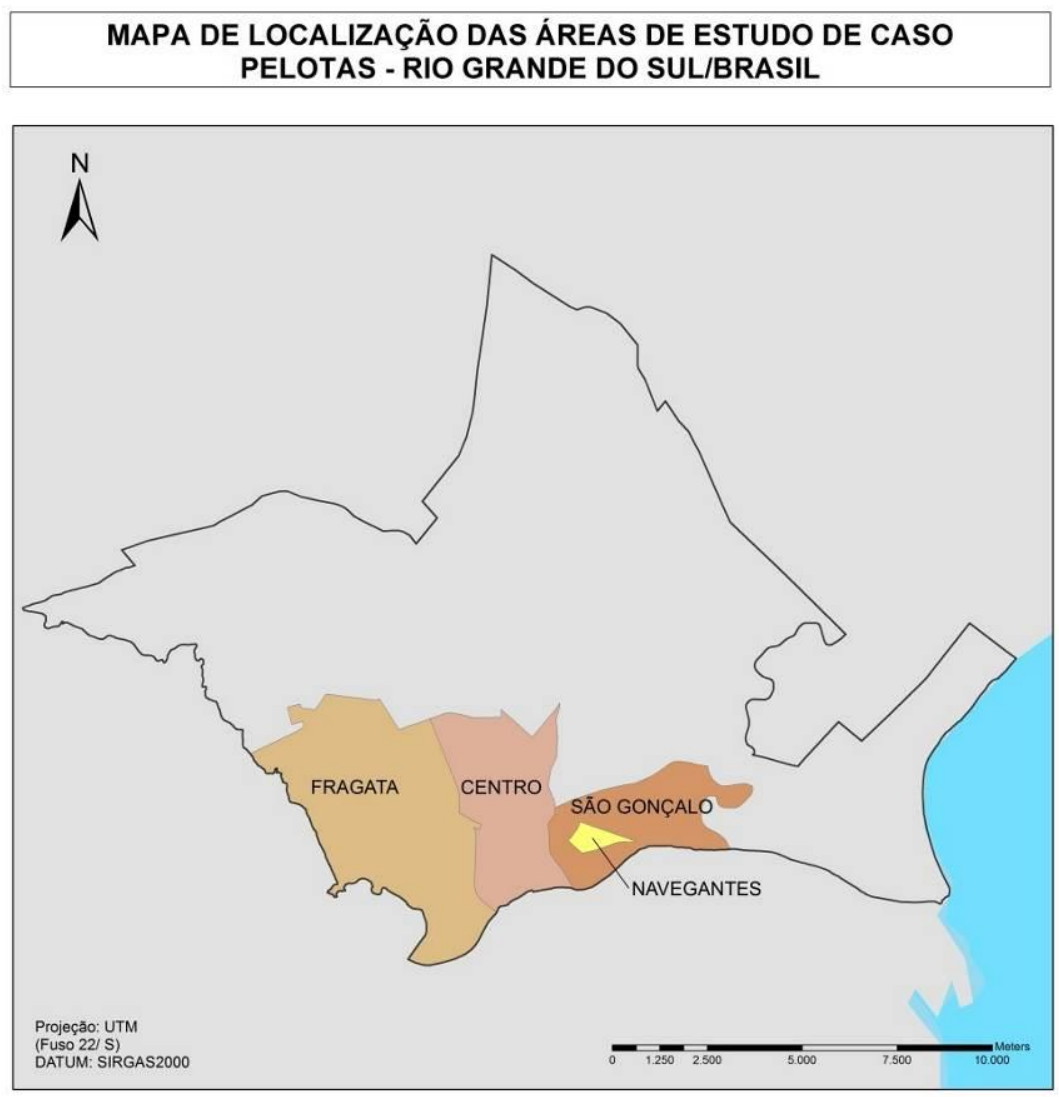

\section{LOCALIZAÇÃO DA}

AREA DE ESTUDO
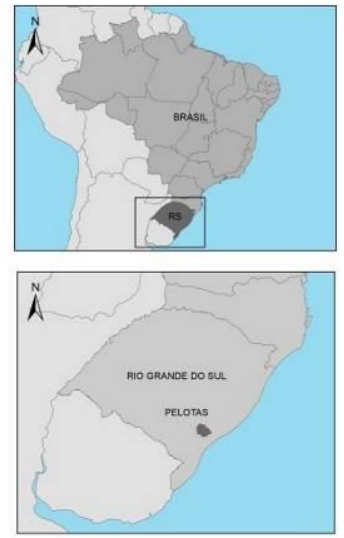

LEGENDA

MICRO REGIĀO

PERIMETRO URBANO

MACROREGAC

CENTRO

FRAGATA
SÃO GONÇALO

MUNICIPIO

LAGOAS

Base cartográfica:Prefeitura de Pelotas, 2017 e

Rio Grande do Sul Porto Alegre: UFRGS, 2010.

Elaborado por: Anelize Milano Cardoso
Data: Julho de 2018

Figura 1 - Área do estudo de caso -

Fonte: PLACE AGE (2018)

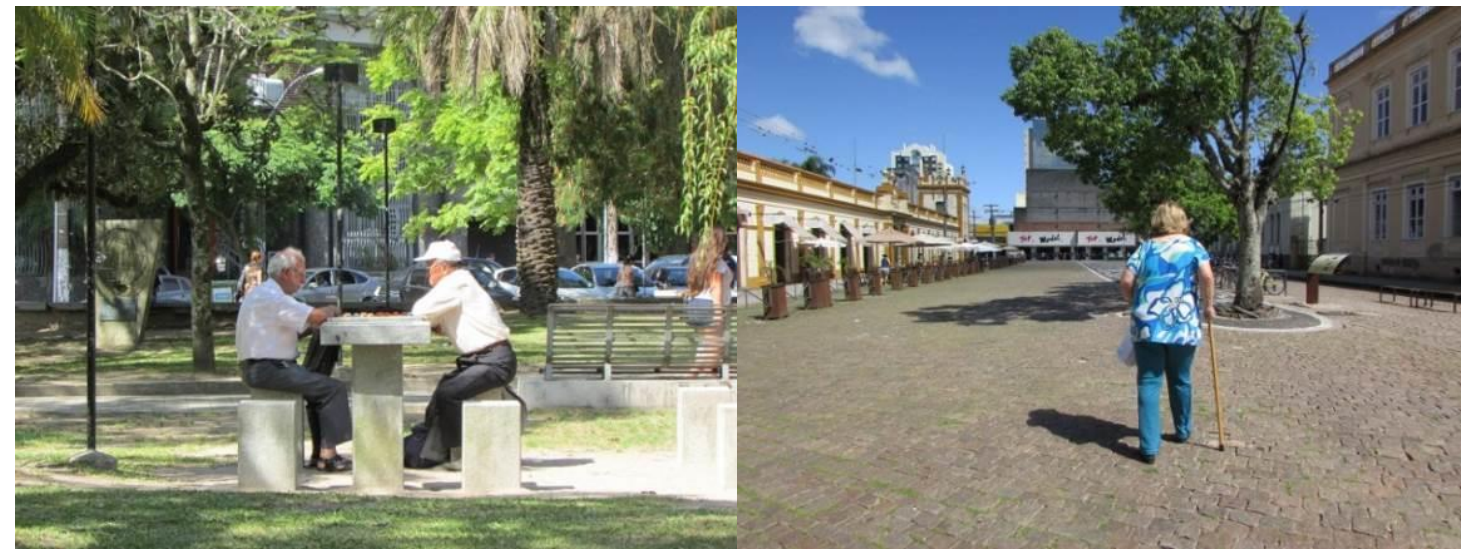

Figura $2-1^{\circ}$ recorte -

Fonte: Autoras (2017) 


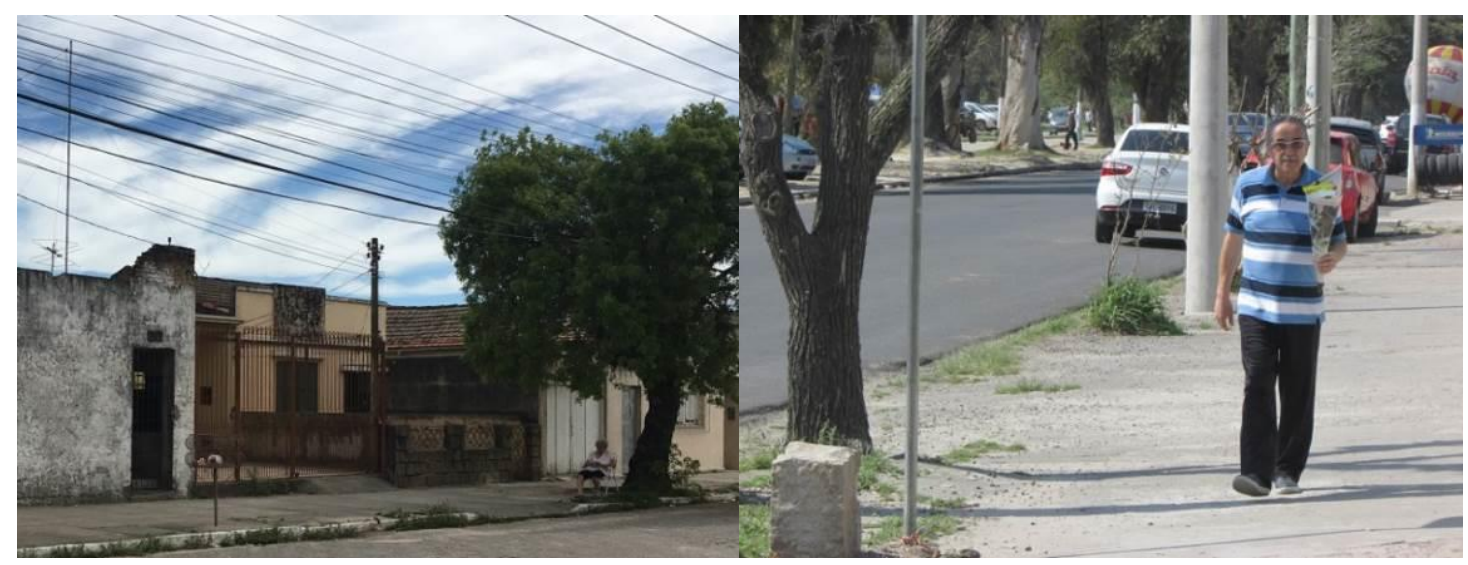

Figura $3-2^{\circ}$ recorte -

Fonte: Autoras (2017)

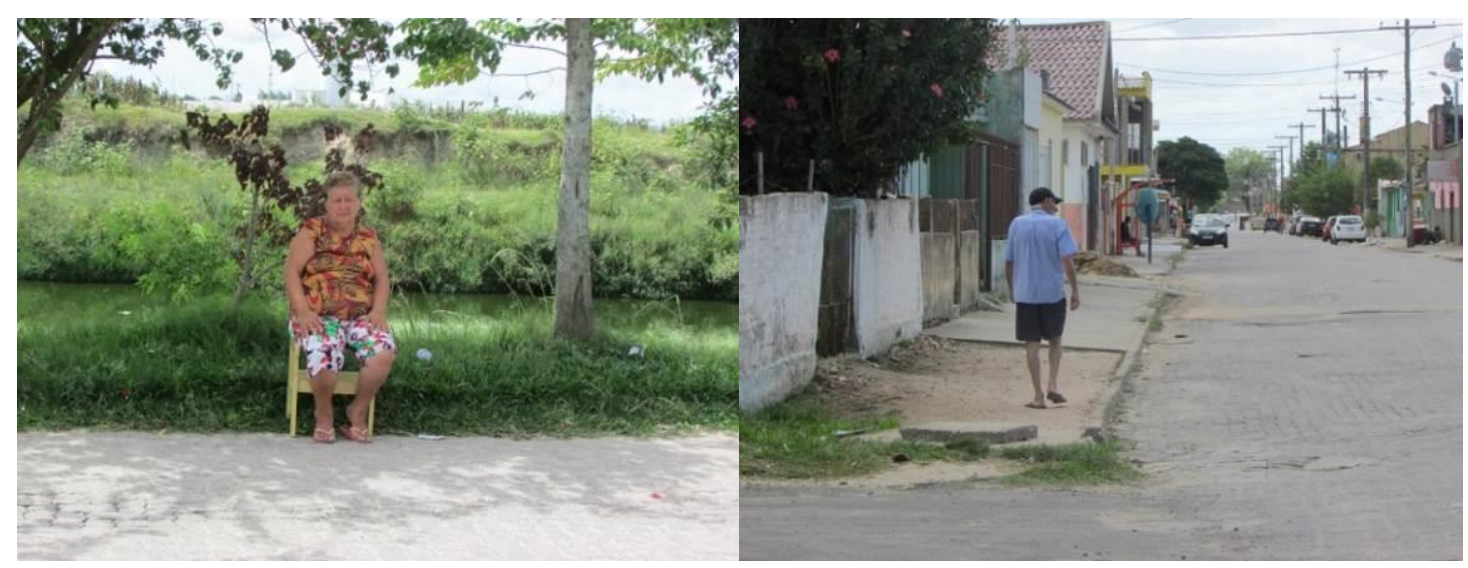

Figura $4-3^{\circ}$ recorte -

Fonte: Autoras (2017)

\subsection{Coleta de Dados}

Os métodos de coleta de dados utilizados foram levantamento bibliográfico, documental e de campo, este divido em:

- Mapas mentais: elaborados no ambiente residencial dos 08 participantes/recorte e acompanhados de entrevista estruturada para coletar informações relevantes às variáveis centradas no usuário. A amostra seguiu o tipo não probabilística por conveniência, ao abordálos em ambiente público. Os voluntários possuíam sessenta anos ou mais de idade e residiam nos recortes.

- Levantamento físico: verificação dos indicadores centrados no ambiente realizado em 04 locais/recorte. Para a definição destes, contabilizaram-se as ruas presentes nos mapas mentais e identificaramse áreas que incluíam as ruas citadas com maior frequência.

- Mapas comportamentais: registro da presença de idosos nas mesmas áreas do levantamento físico. Os locais foram observados pela manhã e à tarde, em dois dias de verão e dois de inverno, sendo um dia útil e outro no final de semana. Elaboraram-se 96 mapas. 


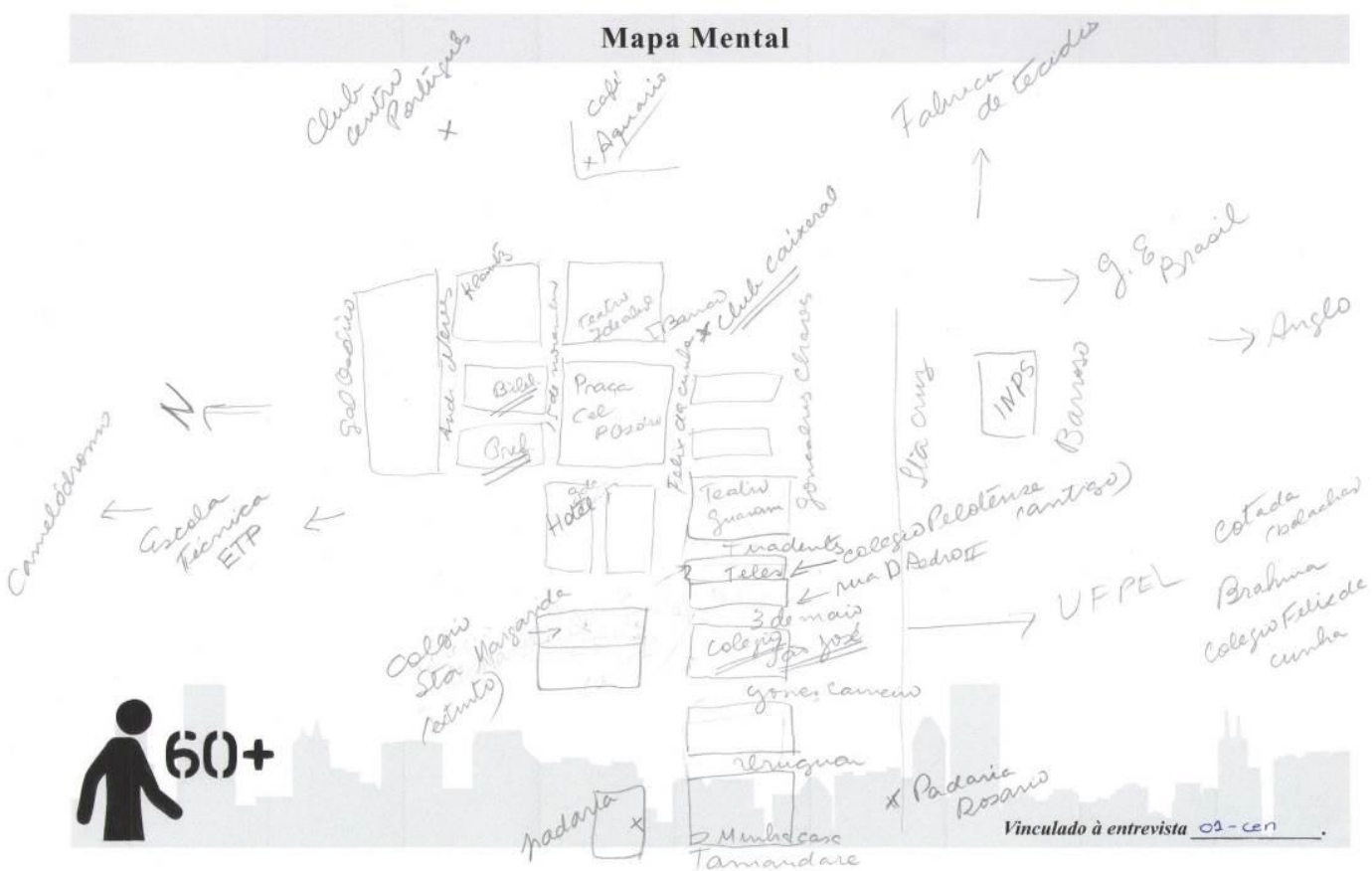

Figura 5 - Exemplo de Mapa Mental -

Fonte: Autoras (2017)

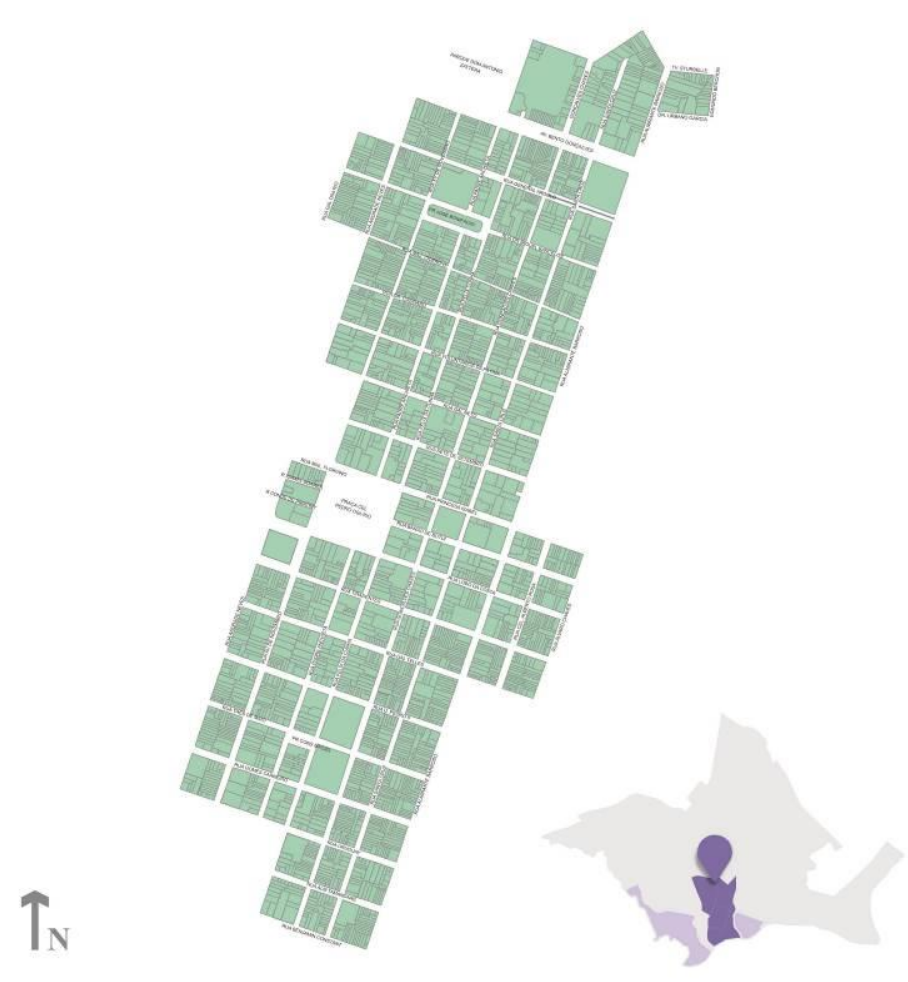

Figura $6-1^{\circ}$ recorte (no Centro) Fonte: Autoras (2017) 


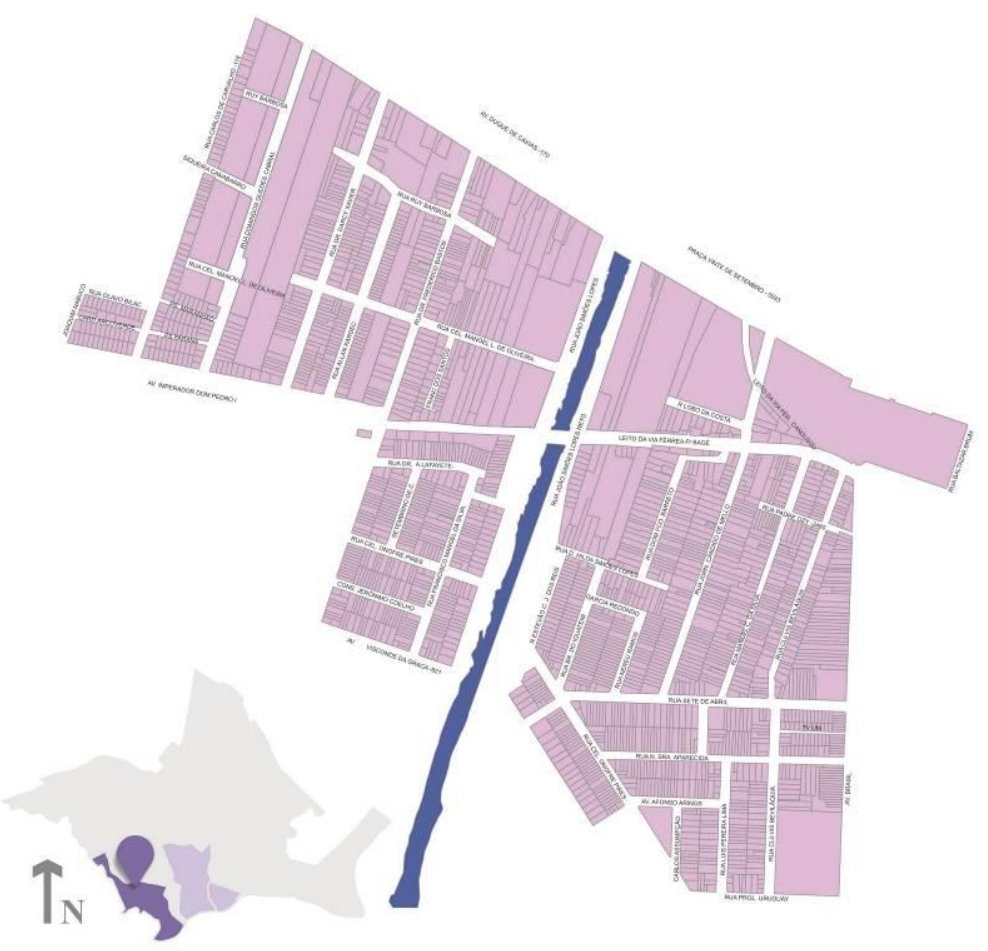

Figura $7-2^{\circ}$ recorte (no Fragata) -

Fonte: Autoras (2017)

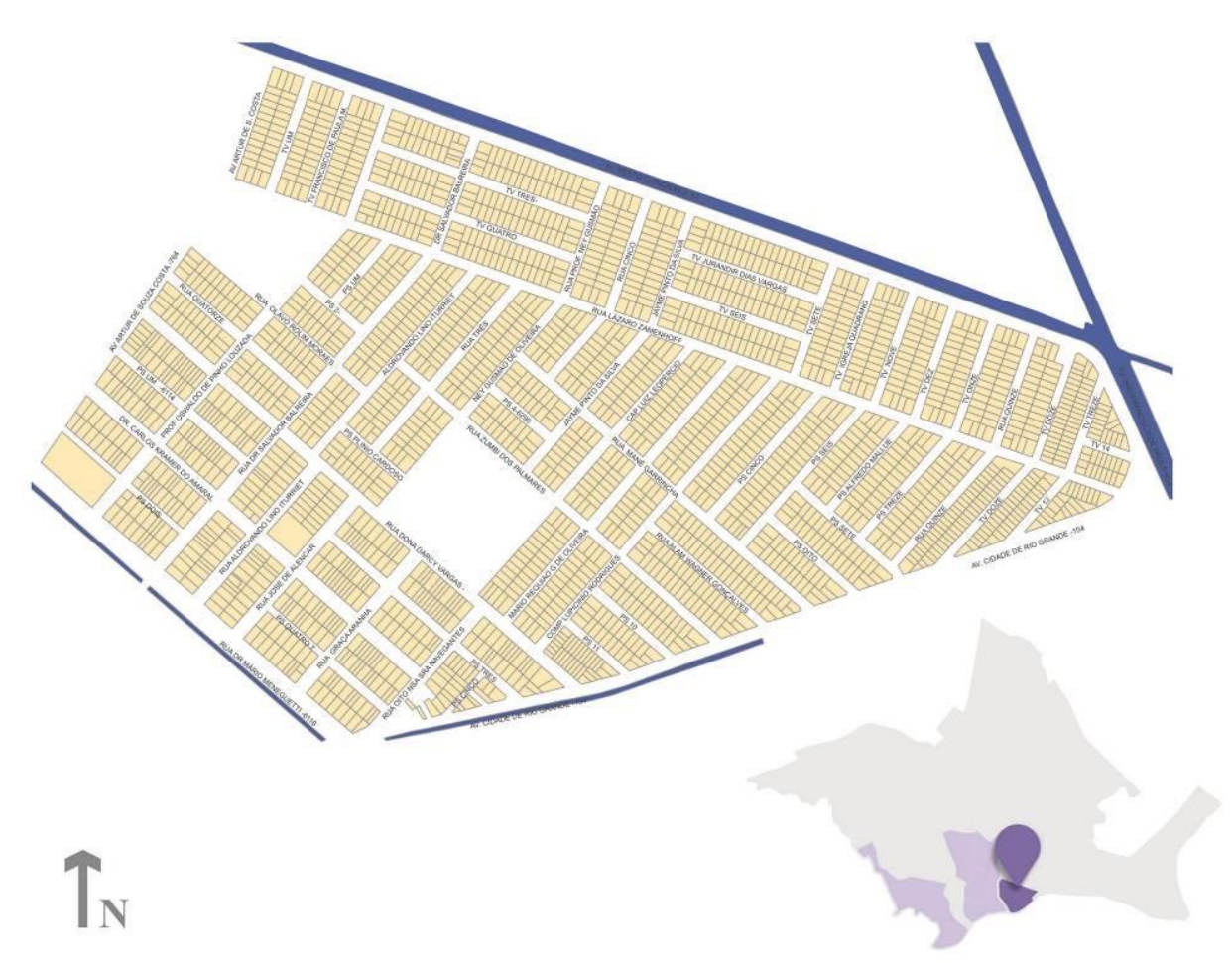

Figura 8 - $3^{\circ}$ recorte (no São Gonçalo) Fonte: Autoras (2017) 


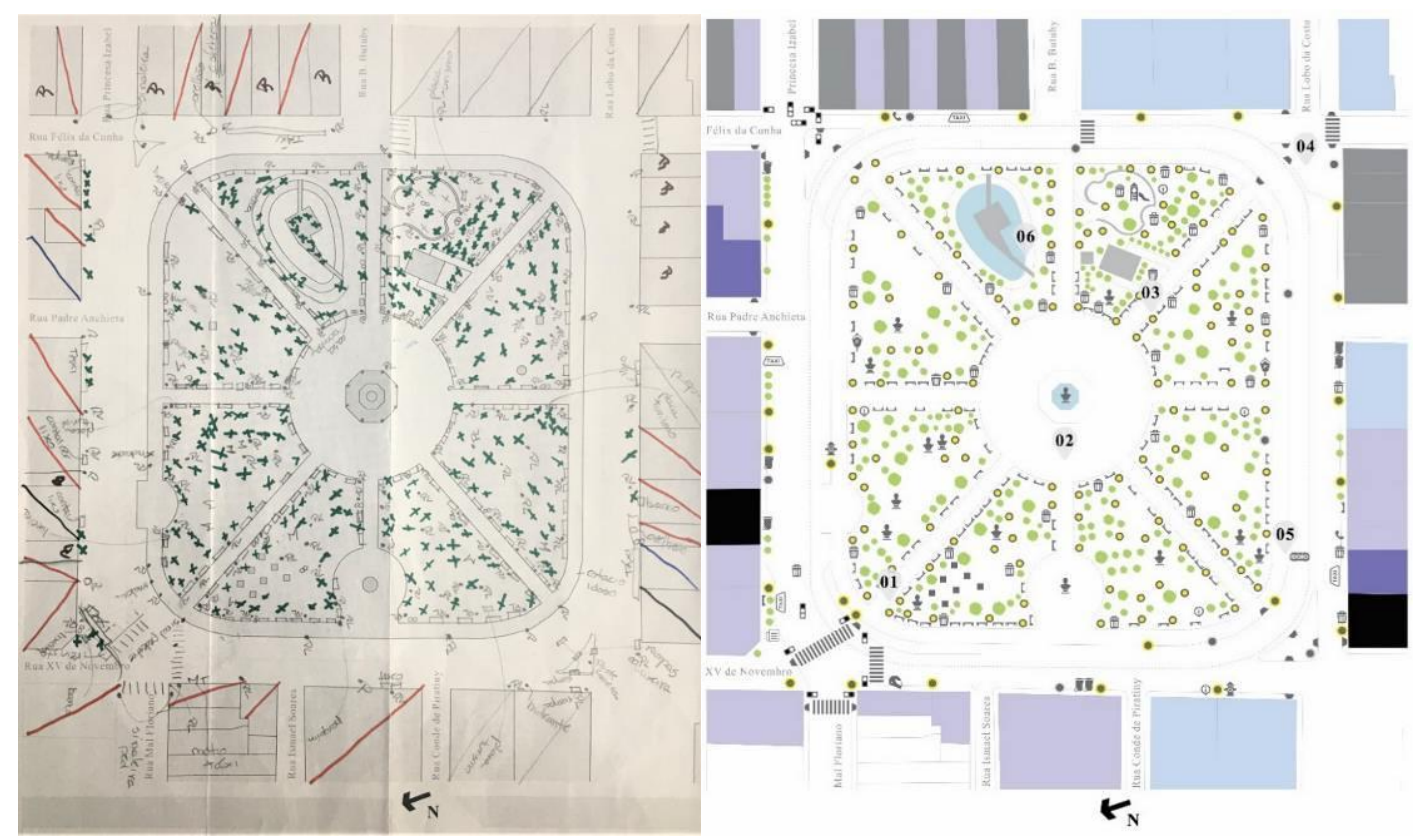

Figura 9 - Levantamento físico, exemplo do registro in loco e na base digital Fonte: Autoras (2017)

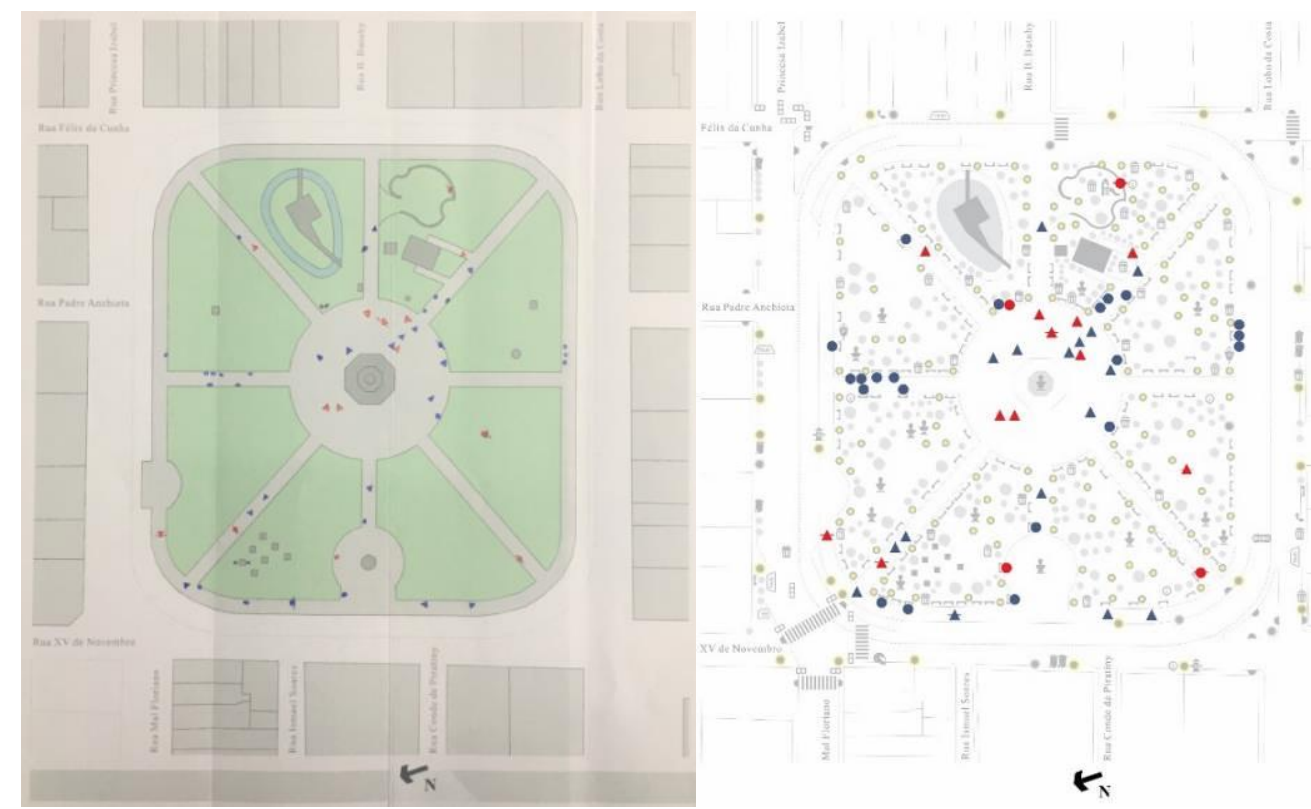

Figura 10 - Levantamento comportamental, exemplo do registro in loco e na base digital Fonte: Autoras (2017)

\subsection{Análise dos Resultados}

- Mapas mentais: foram examinados com o auxílio do aplicativo para dispositivos móveis, MMental2. Ao passar os mapas do meio analógico ao digital, substituíram-se as representações leigas pela simbologia que classifica as inserções em: Marcos, Nós, Limites, Vias e Bairros (LYNCH, 1999). A sobreposição dos mapas individuais viabilizou a composição de mapas coletivos.

2 Desenvolvido no projeto de Pesquisa SOCIOTIC, da Rede Moradia e Tecnologia Social (Rede Morar TS) do FINEP, foi coordenado pelas Profa. Nirce Saffer Medvedovski e Profa. Adriane Borda da Silva. 
- Levantamento físico: contou com uma prancha de dados para cada uma das 12 áreas, contendo: planta baixa, análise dos indicadores centrados no ambiente e o registro fotográfico.

- Mapas comportamentais: foram organizados em pranchas individuais e sobrepostos conforme a necessidade de análise. Exemplo: criaram-se mapas de sobreposição das informações identificadas na Praça Coronel Pedro Osório.

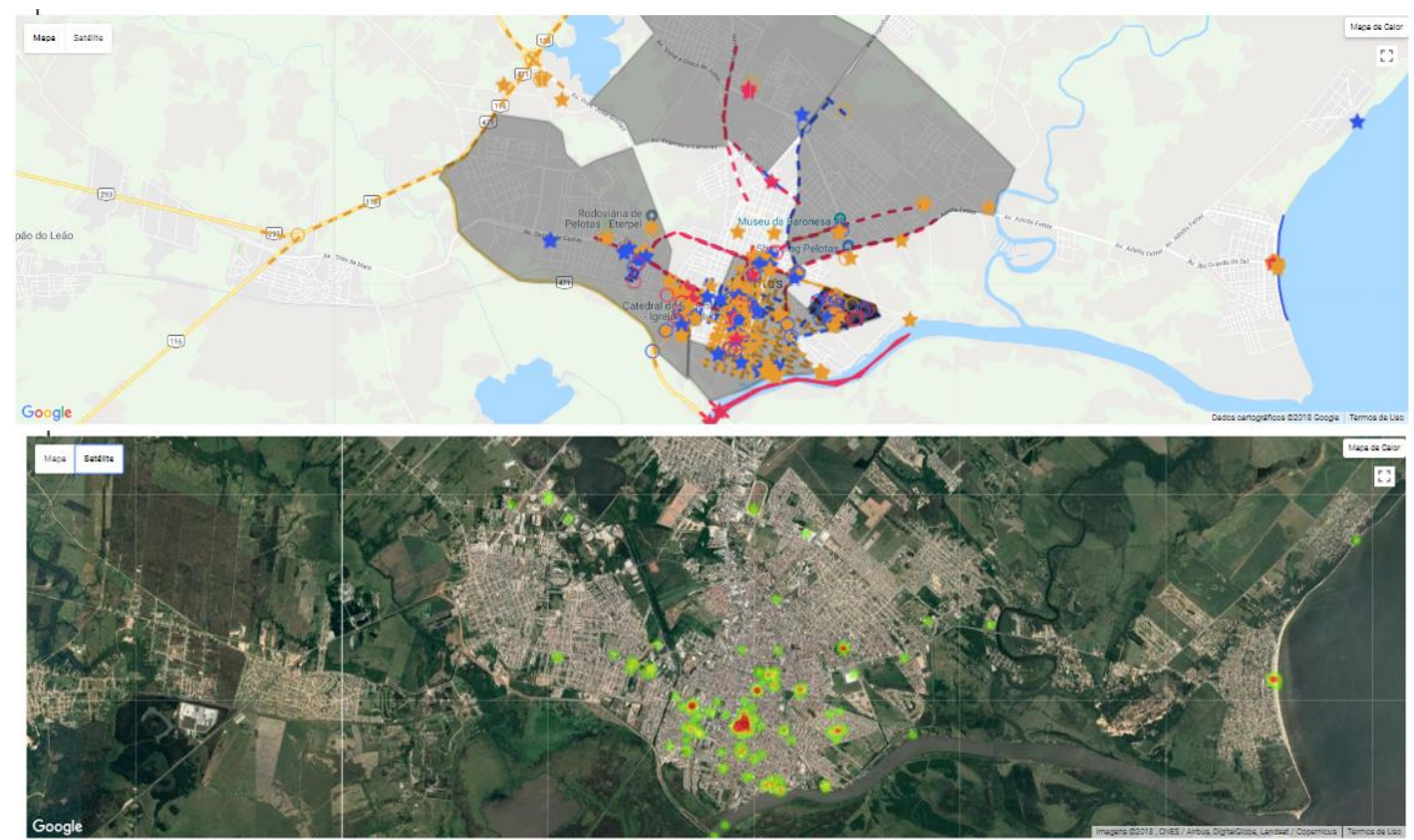

Figura 11 - Mapa mental, exemplo de mapas coletivo e de manchas de calor relativas ao elemento "Marcos" -

Fonte: Autoras (2018)

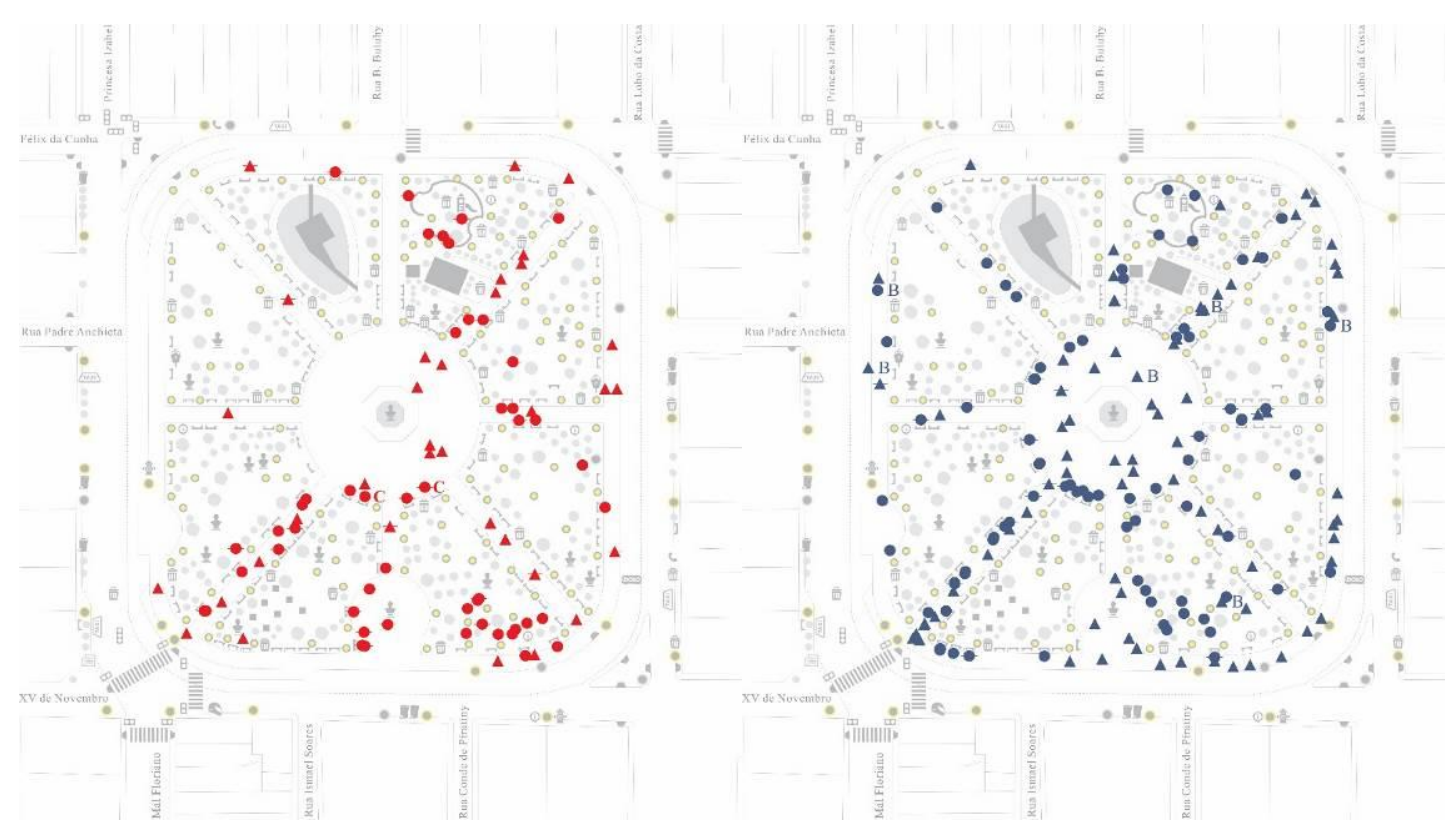

Figura 12 - Mapas Comportamentais Coletivos da sobreposição dos levantamentos realizados aos sábados, divididos em gênero feminino e masculino -

Fonte: Autoras (2018) 


\section{RESULTADOS}

\subsection{Mapas Mentais}

Registrou-se que $75 \%$ e $50 \%$ dos entrevistados nos $1^{\circ}$ e $3^{\circ}$ recortes (Centro e São Gonçalo) vão com maior frequência a lugares nos próprios bairros e que $62 \%$ dos respondentes do $2^{\circ}$ recorte (Fragata) vão a locais fora do bairro. Nenhum idoso do $1^{\circ}$ recorte usufrui de transporte coletivo e $37 \%$ dos entrevistados dos $2^{\circ}$ e $3^{\circ}$ recortes utilizam ônibus. Os participantes dos $1^{\circ}, 2^{\circ}$ e $3^{\circ}$ recortes utilizam, em média, entre 19, 30 e 23,75 minutos em deslocamento.

Quanto às variáveis centradas no usuário, em relação à cidade, †em-se que os idosos do $3^{\circ}$ recorte (São Gonçalo) a percebem de uma forma mais segura, legível e confortável que os demais. Entretanto, os idosos deste recorte tendem a percebê-la de forma menos acessível, atrativa e bonita. Ao repetir as perguntas para uma reflexão sobre o bairro onde moram, os idosos do $3^{\circ}$ recorte o percebem como menos seguro, acessível, atrativo, confortável e bonito. Quando indagados sobre a legibilidade, os respondentes do $2^{\circ}$ recorte (Fragata) avaliaram de forma menos legível.

\section{Quadro 1 - Resultado da percepção das variáveis em relação à cidade}

\begin{tabular}{|c|c|c|c|}
\hline \multirow{2}{*}{$\begin{array}{l}\text { Você acha } \\
\text { Pelotas uma } \\
\text { cidade }\end{array}$} & \multicolumn{3}{|c|}{ Respostas positivas (\%) } \\
\hline & $1^{\circ}$ recorte & $2^{\circ}$ recorte & $3^{\circ}$ recorte \\
\hline segura? & 0 & 0 & 37 \\
\hline acessível? & 63 & 75 & 50 \\
\hline atrativa? & 75 & 63 & 37 \\
\hline confortável? & 75 & 50 & 75 \\
\hline bonita? & 75 & 100 & 63 \\
\hline legível? & 75 & 50 & 88 \\
\hline
\end{tabular}

Fonte: Autoras (2019)

\section{Quadro 2 - Resultado da percepção das variáveis em relação ao bairro}

\begin{tabular}{|l|c|c|c|}
\hline \multirow{2}{*}{$\begin{array}{l}\text { Você acha seu } \\
\text { bairro um lugar }\end{array}$} & \multicolumn{3}{|c|}{ Respostas positivas (\%) } \\
\hline segura? & $1^{\circ}$ recorte & $2^{\circ}$ recorte & $3^{\circ}$ recorte \\
\hline acessível? & 37 & 50 & 25 \\
\hline atrativa? & 100 & 88 & 37 \\
\hline confortável? & 75 & 50 & 25 \\
\hline bonita? & 63 & 88 & 50 \\
\hline legível? & 50 & 88 & 25 \\
\hline
\end{tabular}

Fonte: Autoras (2019)

Quanto às inserções:

- $1^{\circ}$ recorte - 157 inserções. As inserções concentraram-se no Centro, destacando a Praça Coronel Pedro Osório, a Catedral de São Francisco de Paula e a Praia do Laranjal. 
- $2^{\circ}$ recorte - 174 inserções. Inseriram-se informações no bairro e em outras regiões, destacando o Instituto Federal de Educação, Ciência e Tecnologia Sul-rio-grandense (IFSUI), localizado no $2^{\circ}$ recorte.

- $3^{\circ}$ recorte - 190 inserções, ineditamente foram identificadas 09 inserções do elemento Bairro, ou seja, que identifica territórios mais amplos na cidade. Apresentaram informações locais e de outras regiões, destacando a Unidade Básica de Atendimento Imediato e o supermercado BIG, localizados no bairro de moradia.

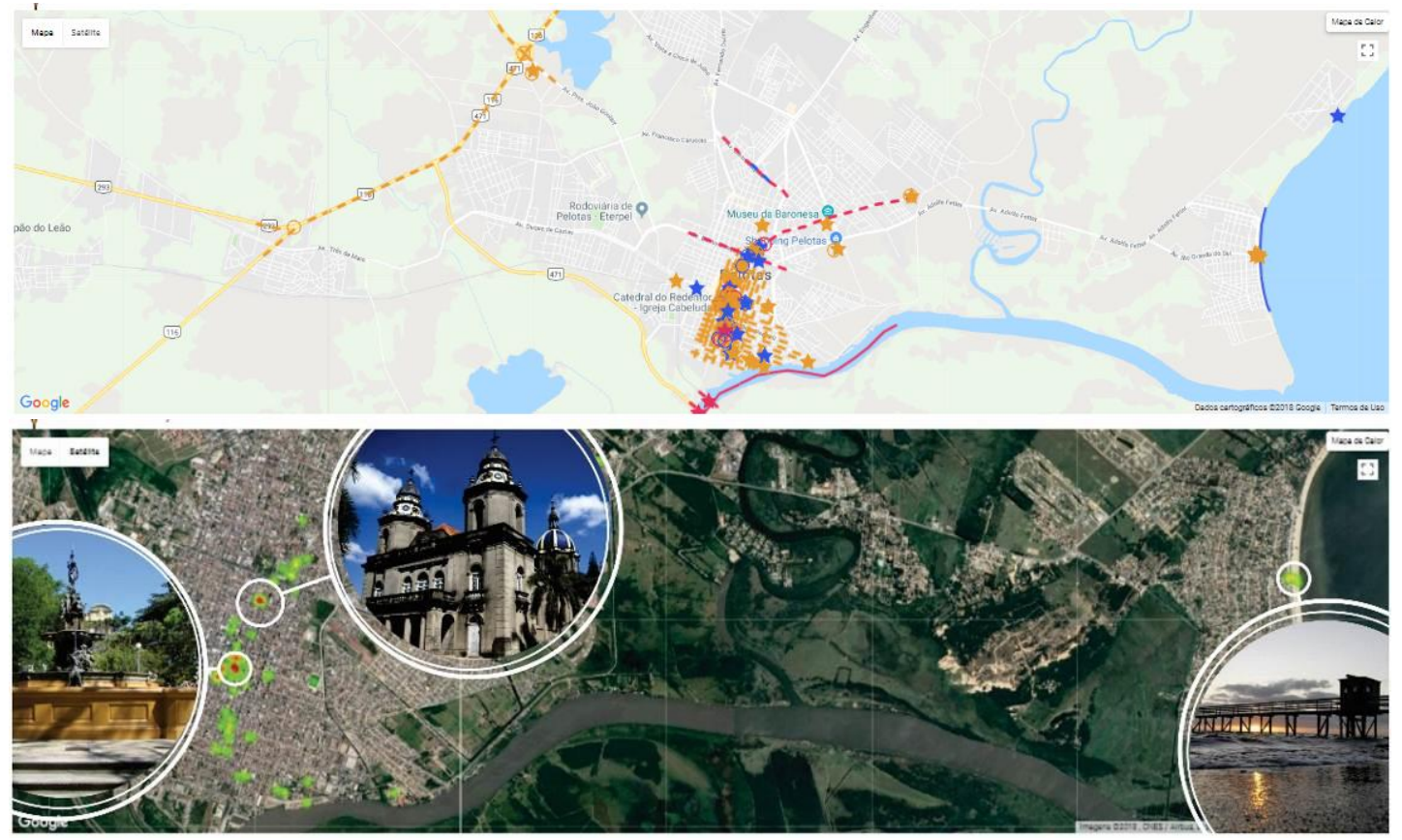

Figura $13-1^{\circ}$ recorte, mapa mental coletivo e manchas de calor Fonte: Autoras (2018)

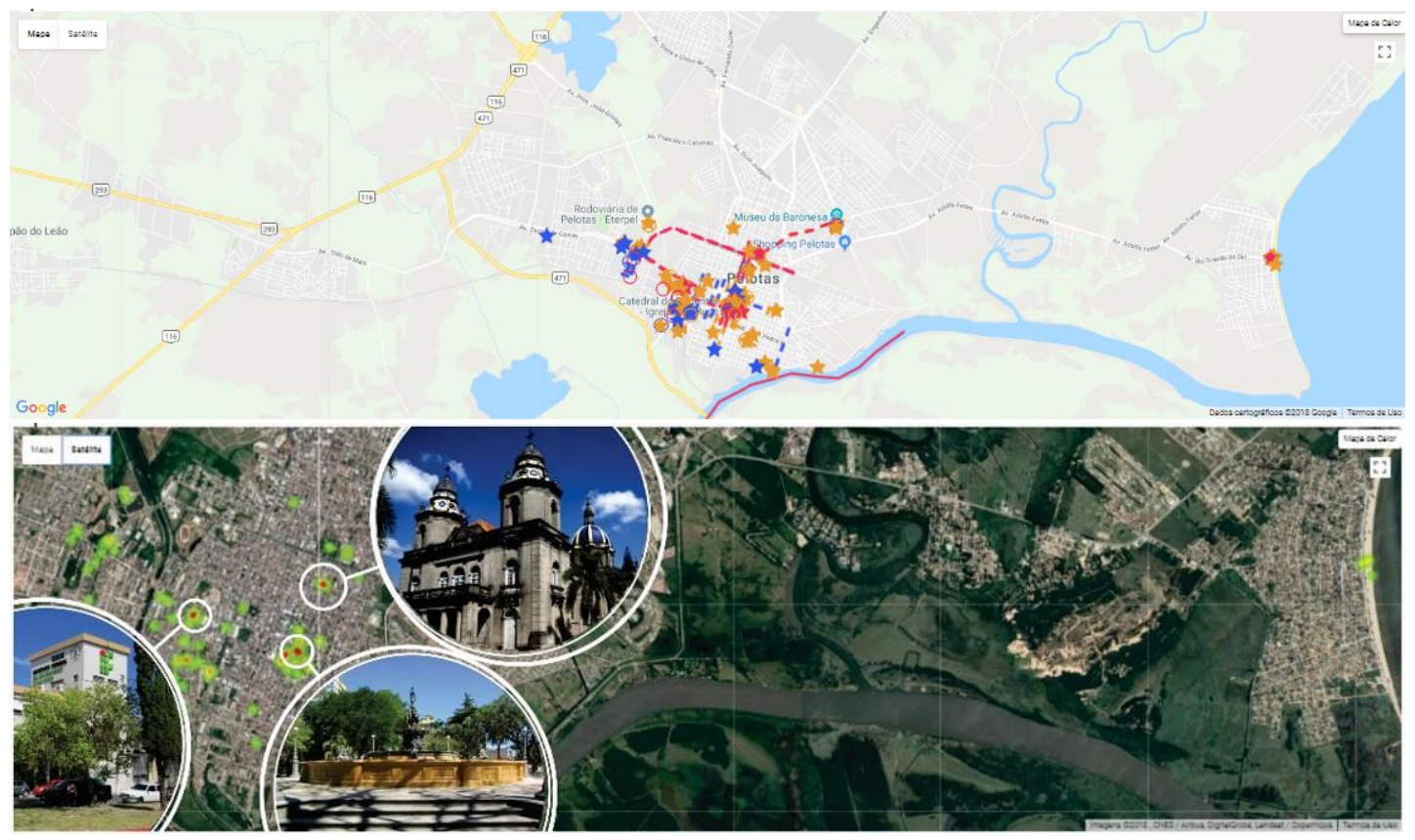

Figura $14-2^{\circ}$ recorte, mapa mental coletivo e manchas de calor Fonte: Autoras (2018) 


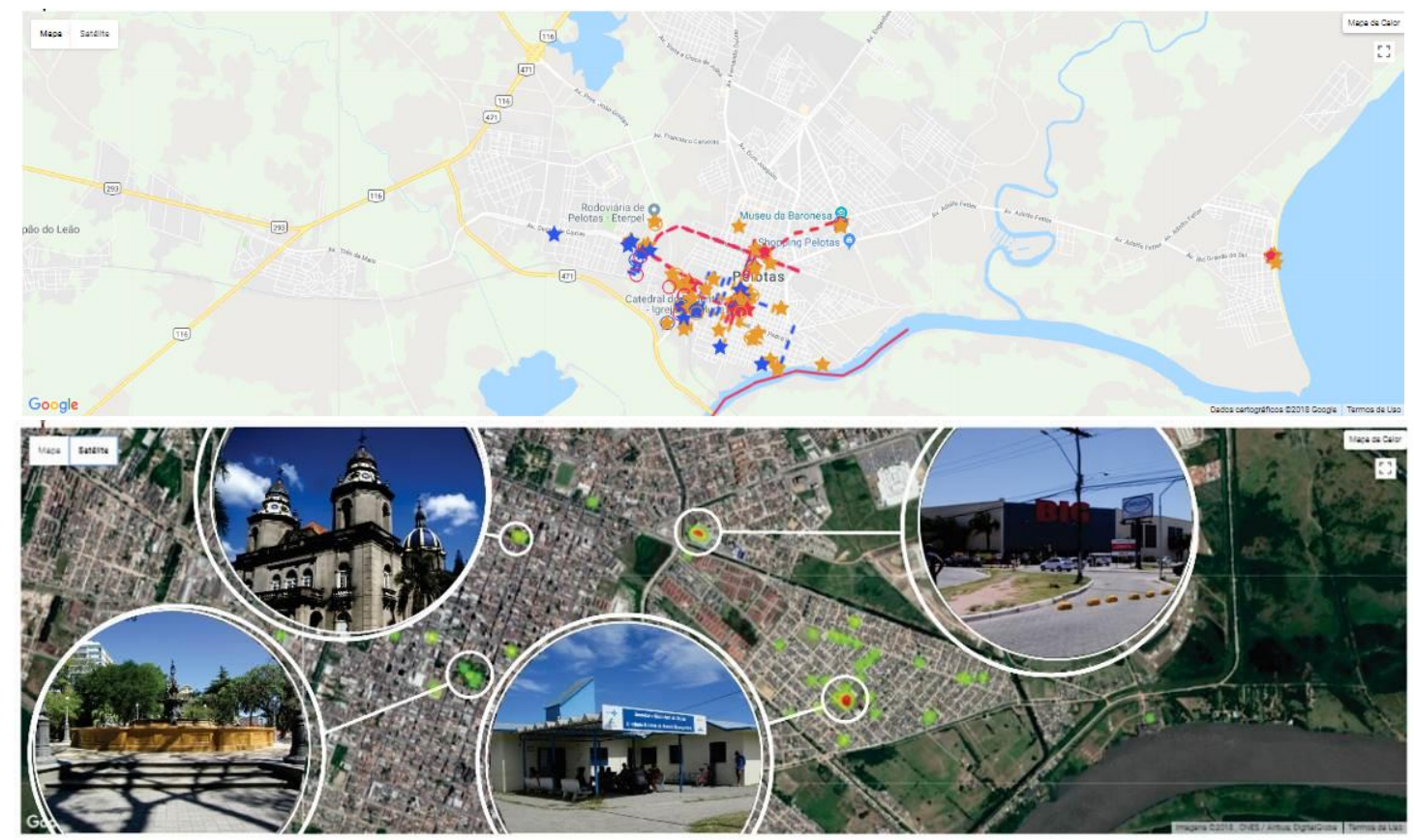

Figura $15-3^{\circ}$ recorte, mapa mental coletivo e manchas de calor Fonte: Autora (2018)

\subsection{Levantamento Físico}

- $1^{\circ}$ Recorte (Quadro 3): caracteriza-se pela grande presença de equipamentos e infraestrutura de apoio, equipamentos de trânsito e pela limpeza urbana. Das quatro regiões, três atingiram o conceito qualitativo máximo e, assim, este recorte apresenta os únicos conceitos máximos da presença de indicadores centrados no ambiente (na Praça Cel Pedro Osório e no entorno do Mercado Público) e a única região onde os equipamentos para acessibilidade foram avaliados como suficientes (na Praça Cel Pedro Osório).

- $2^{\circ}$ Recorte (Quadro 4): caracteriza-se pela presença de equipamentos e infraestrutura de apoio e de locais distribuidores de fluxo social; pela fraca oferta de equipamentos para acessibilidade e pela presença de lixo. Resulta-se em duas avaliações boas, uma intermediária e uma ruim que, comparadas aos demais recortes, o posicionam em um nível intermediário de qualidade física.

- $3^{\circ}$ Recorte (Quadro 5): destaca-se pela presença de elementos naturais e pela baixa oferta de equipamentos e infraestrutura de apoio, para acessibilidade e de trânsito. Constatou-se uma imensa quantidade de lixo depositado junto aos elementos naturais (canteiros e canais hídricos). Resulta-se em 04 avaliações ruins, o que atribui ao $3^{\circ}$ recorte 0 pior nível de qualidade física. 
Uso do Solo Predominante

locais de consumo e bens de serviços residencial

locais de lazer e prática de at. física

\section{Conceito Qualitativo}

presença de 0 a 3 indicadores centrados no ambiente

presença de 4 a 5 indicadores centrados no ambiente

presença de 6 a 8 indicadores centrados no ambiente

Figura 16 - Legenda dos aspectos urbanos -

Fonte: Autoras (2018)

Quadro $3-1^{\circ}$ recorte, análise do perfil urbano

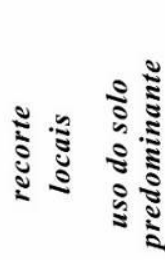

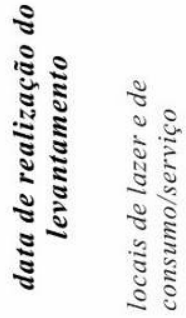

indicadores centrados no ambiente
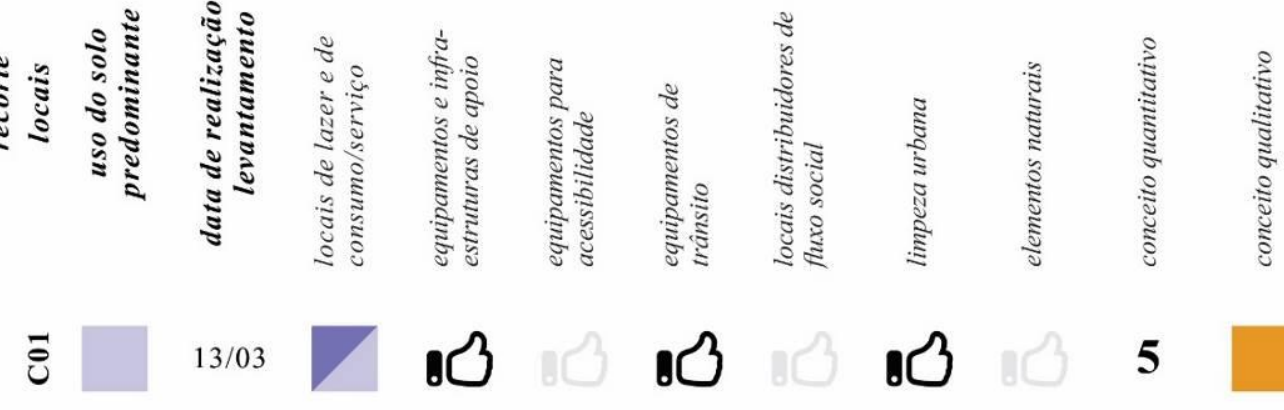

$13 / 03$

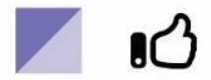

80

80

5

ㅇํํ $22 / 03$

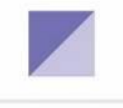

. 0.08

. 3 : 87

$\div$ ?

$22 / 03$

ac

.

7

Ð

10

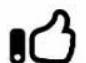

๑ \& 6

Fonte: Autoras (2018)

Quadro $4-2^{\circ}$ recorte, análise do perfil urbano
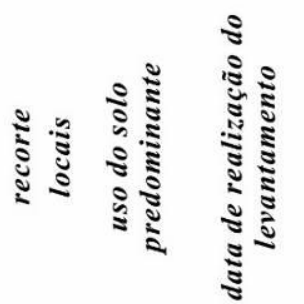

indicadores centrados no ambiente
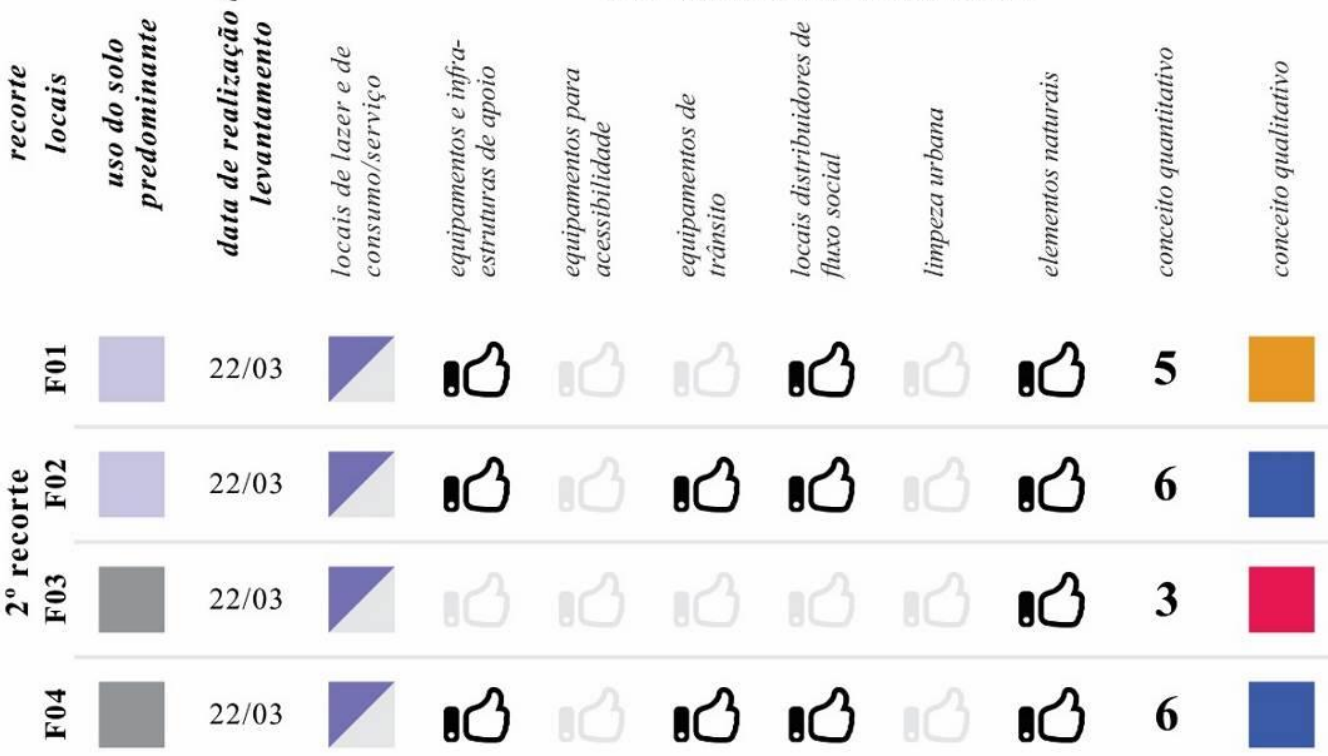

Fonte: Autoras (2018) 
Quadro $5-3^{\circ}$ recorte, análise do perfil urbano

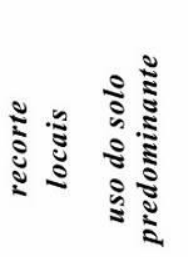

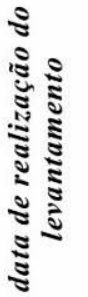
indicadores centrados no ambiente

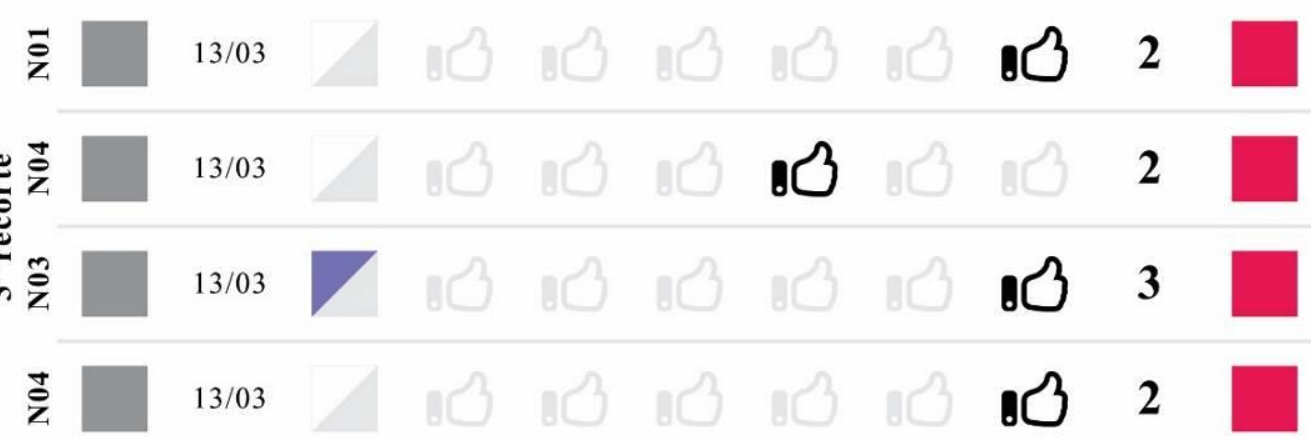

Fonte: Autoras (2018)

Quadro 6 - Ilustração do perfil urbano

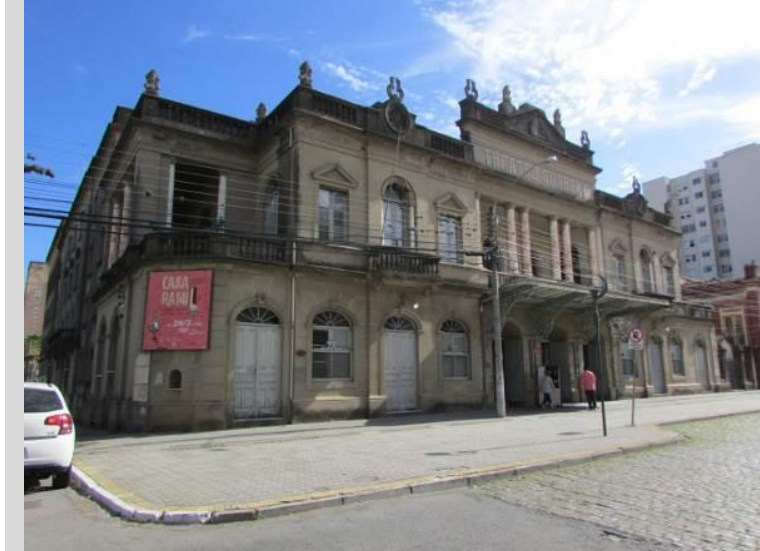

Teatro Guarany ( $1^{\circ}$ recorte)

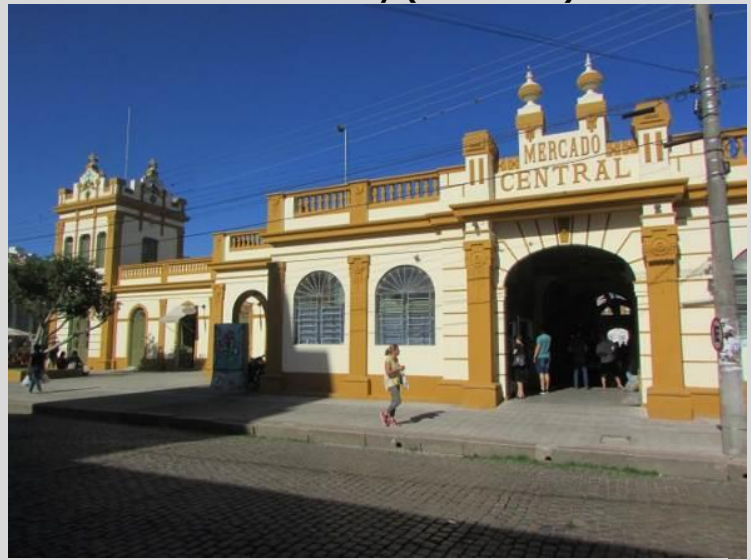

Mercado Público ( $1^{\circ}$ recorte)

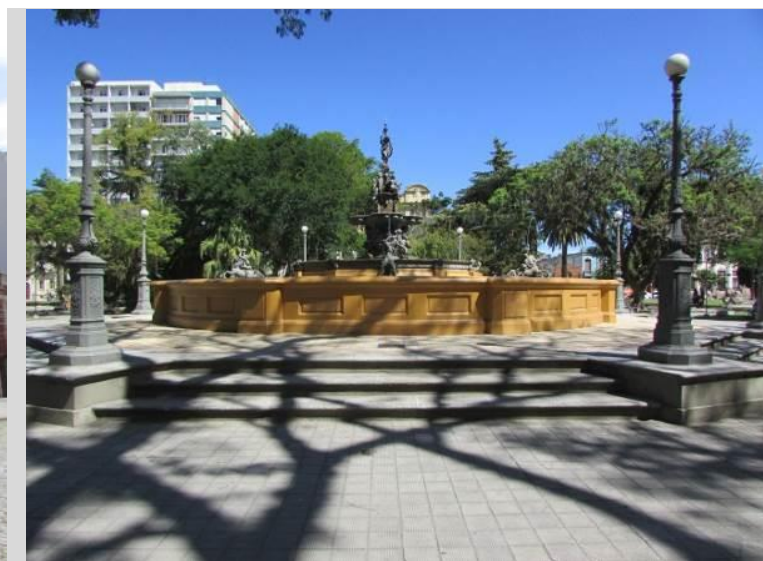

Praça Cel. P. Osório ( $1^{\circ}$ recorte)

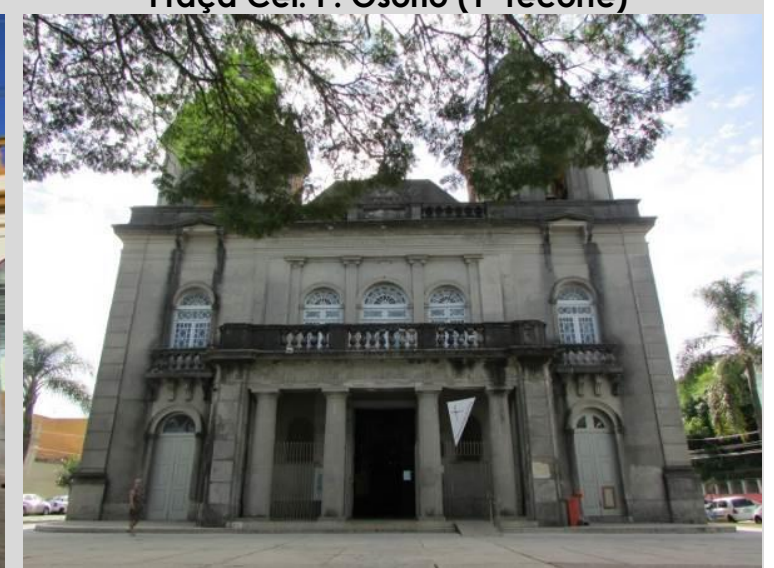

Catedral S.F. de Paula ( $1^{\circ}$ recorte) 


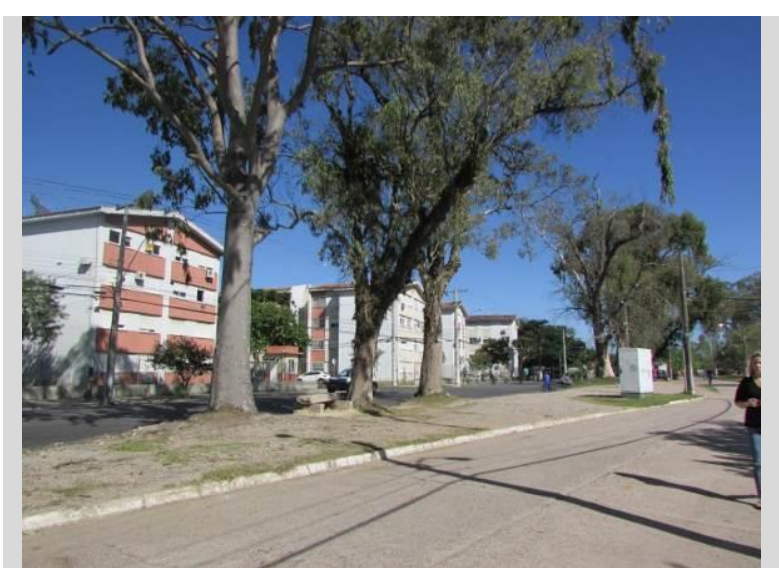

Av. Duque de Caxias ( $2^{\circ}$ recorte)

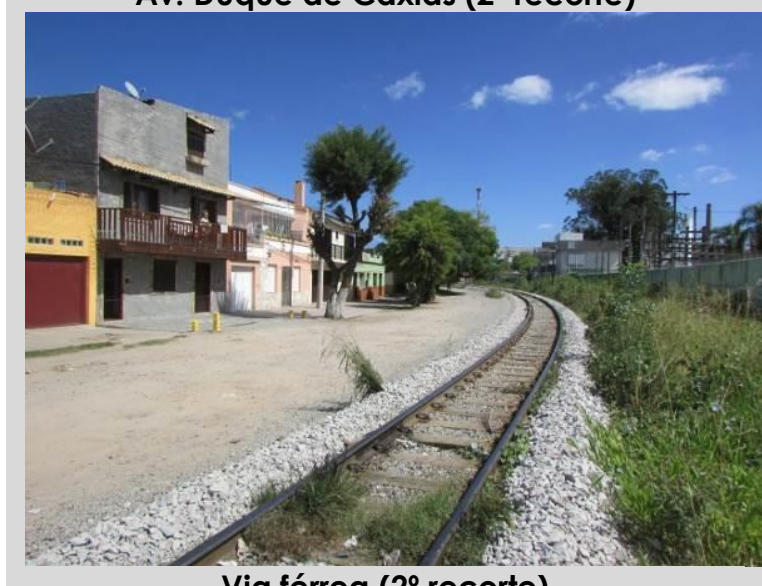

Via férrea $\left(2^{\circ}\right.$ recorte $)$

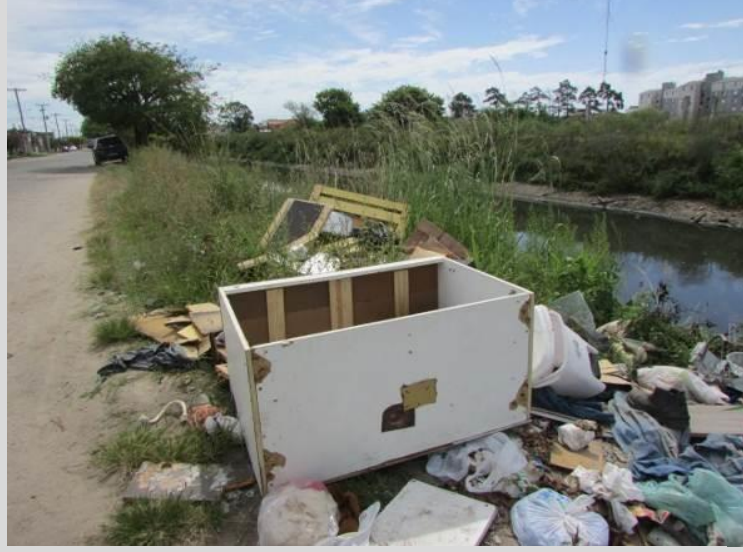

Av. Bento Gonçalves ( $3^{\circ}$ recorte)

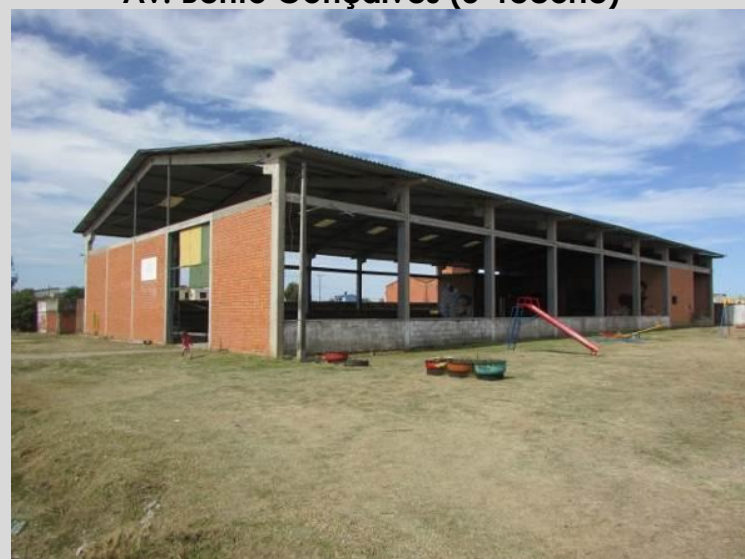

Ginásio de esportes ( $3^{\circ}$ recorte)

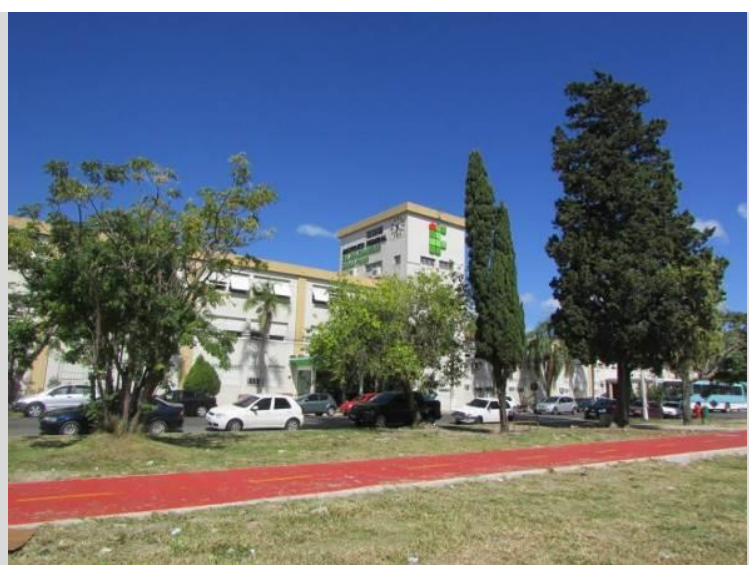

IFSul ( $2^{\circ}$ recorte)

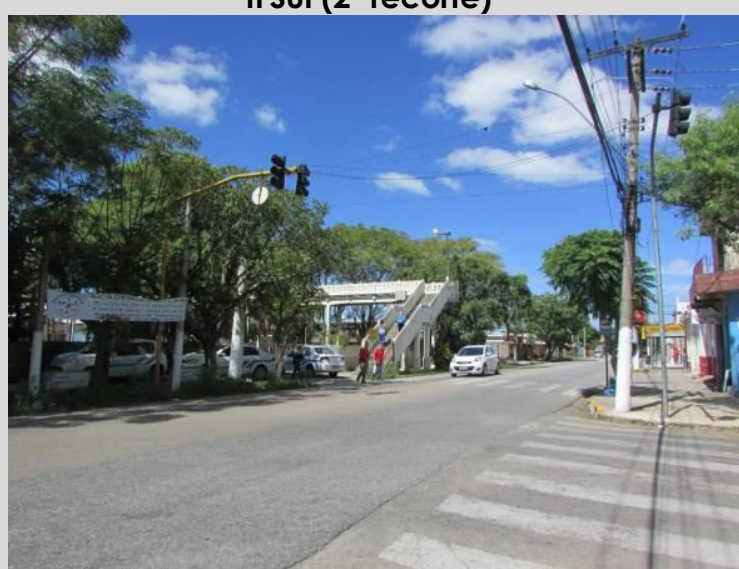

Avenida Brasil ( $2^{\circ}$ recorte)

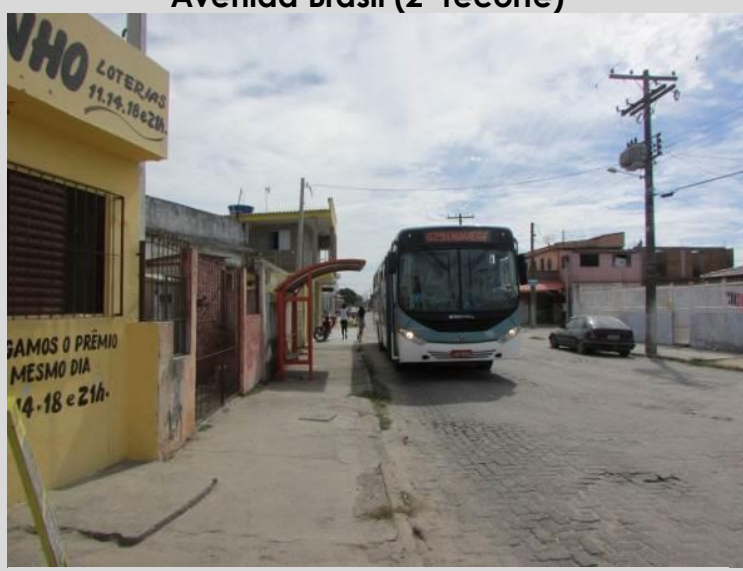

Rua Lázaro Zamenhoff ( $3^{\circ}$ recorte)

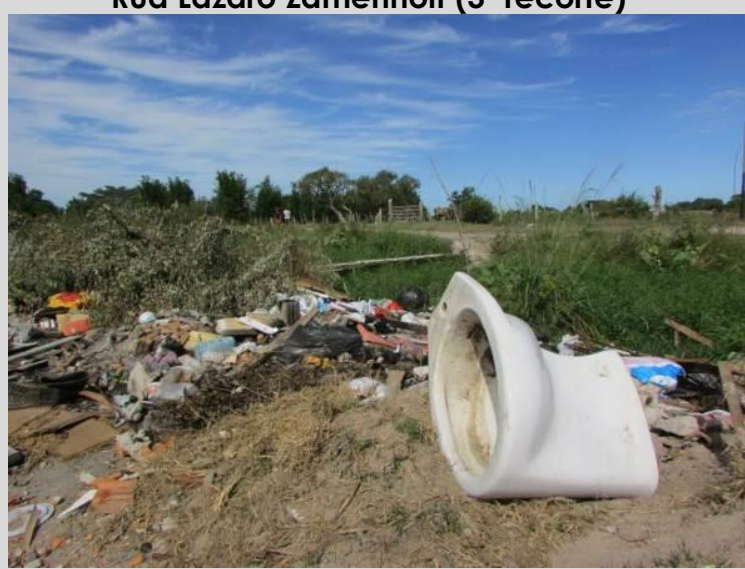

Av. Cidade de RG ( $3^{\circ}$ recorte) 


\subsection{Mapas Comportamentais}

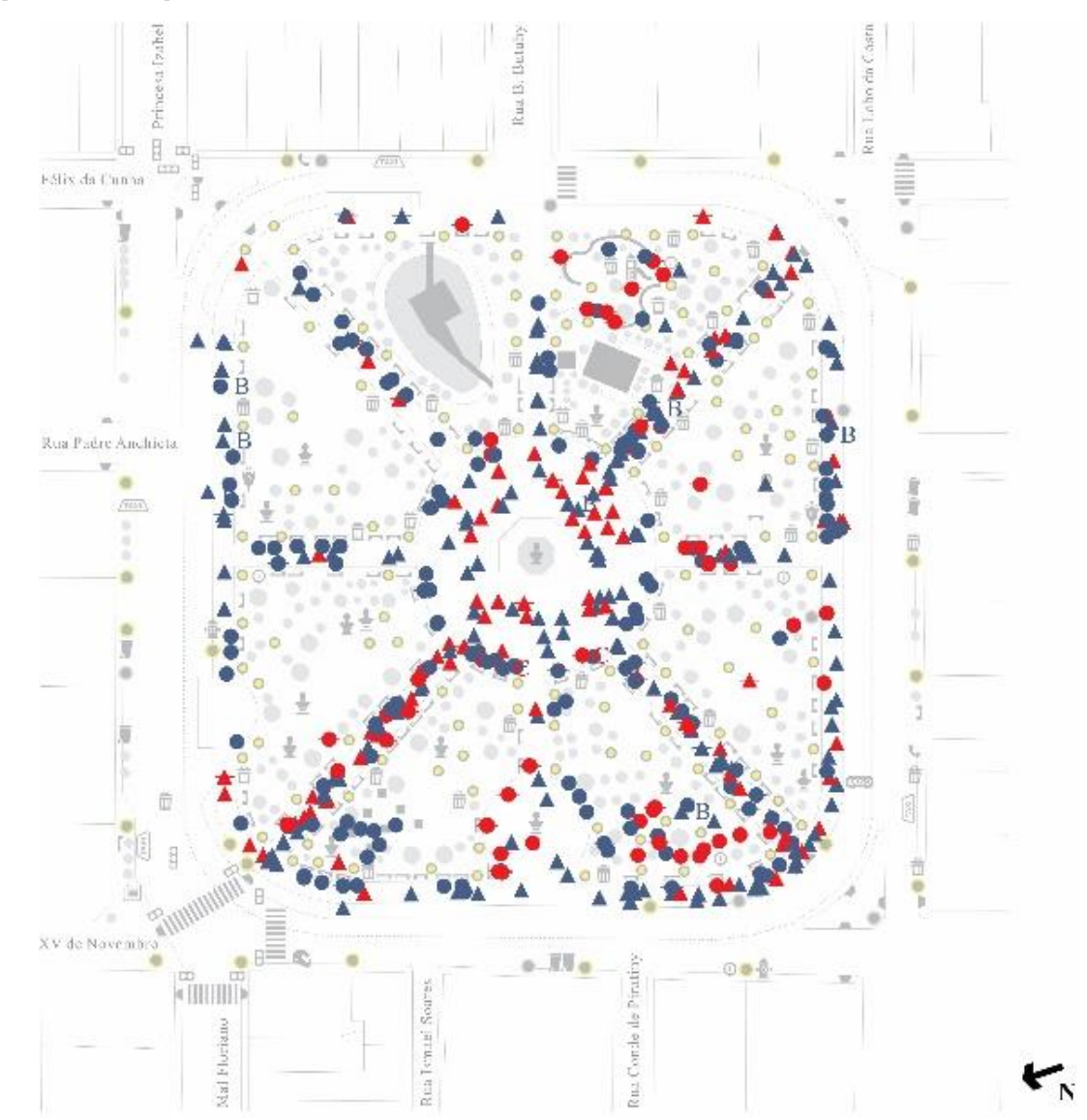

Figura 17 - Exemplo de mapa comportamental final: registro da presença de todos os idosos identificados na Praça Cel Pedro Osório ( $1^{\circ}$ recorte) Fonte: Autoras (2018)

Registraram-se 1.597 idosos: $1.253(78 \%)$ no $1^{\circ}$ recorte, 261 (16\%) no $2^{\circ}$ recorte e $83(6 \%)$ no $3^{\circ}$ recorte; 943 (59\%) do gênero masculino e 654 (41\%) do feminino; 60 (97\%) ciclistas do gênero masculino e 02 (03\%) do feminino; 04 cadeirantes do gênero feminino; e 1.071 (67\%) em movimento e 526 (33\%) em atividade estacionária.

- $1^{\circ}$ recorte - 1.253 idosos: 735 do gênero masculino e 518 do feminino; grande parcela identificada na Praça Cel Pedro Osório e no entorno do Mercado Público (1.148 idosos); 830 em movimento (66\%) e 423 parados (34\%); todos os cadeirantes do estudo estavam neste recorte; e nas regiões do Teatro Guarany (04 pessoas em movimento e 05 paradas) e da Praça Cel Pedro Osório (96 em movimento e 142 paradas), à tarde, ocorreram os únicos registros onde o número de pessoas em atividade estacionária foi superior.

- $2^{\circ}$ recorte - 261 idosos: 160 do gênero masculino e 101 do feminino; 176 (67\%) em movimento e 85 (33\%) paradas; e na Avenida Duque de Caxias ocorreu o maior número de idosos (121 pessoas, $46 \%$ ) e a maior concentração de ciclistas (24 pessoas).

- $3^{\circ}$ recorte - 83 idosos: 48 do gênero masculino e 35 do feminino; o percentual de idosos parados foi o menor dentre os recortes 18 pessoas, $21 \%$ ); e a maior concentração de idosos foi identificada na Rua Lázaro Zamenhoff e próximo ao ginásio de esportes (73 idosos, 88\%). 


\section{CONCLUSÕES}

Conclui-se que os respondentes do Centro efetuam deslocamentos curtos e nos limites do próprio bairro, acarretando na fraca legibilidade municipal. Porém, estimulados pela boa qualidade física do local, avaliam a cidade de forma positiva. Os entrevistados no Fragata afirmaram ir a locais fora do bairro e incluíram a utilização de transporte coletivo. Assim, o tempo e o comprimento dos trajetos se tornaram aumentam, enriquecendo a legibilidade urbana. Influenciados pela boa qualidade física local, Pelotas foi avaliada de forma positiva pelos idosos do Fragata. Os respondentes do São Gonçalo costumam frequentar locais fora do bairro, utilizam ônibus e executam trajetos demorados. Influenciados por esta dinâmica, apresentaram uma legibilidade forte de Pelotas. Porém, motivados pela baixa qualidade física local, avaliaram-na de forma mais negativa.

Assim como, conclui-se que o Centro foi percebido de forma mais positiva pelos moradores do bairro e apresentou uma apropriação intensa; o Fragata foi percebido de forma positiva e apresentou uma apropriação intermediária; e o São Gonçalo foi percebido de forma negativa e apresentou a menor apropriação.

Logo, as reflexões apontam para a influência que a qualidade do ambiente exerce sobre o modo como os idosos o percebem que, por sua vez, influencia na maneira como deste local se apropriam.

Espera-se que a Prefeitura Municipal de Pelotas e os órgãos apoiadores reconheçam a necessidade do desenvolvimento de projetos que qualifiquem o ambiente com o intuito de melhorar a percepção que os idosos do São Gonçalo retêm do cenário municipal e desenvolvam medidas que potencializem a imagem da cidade para os moradores do Centro e Fragata. Além disto, quer-se salientar a necessidade da requalificação dos espaços através de: projetos que incentivem os moradores do Centro a usufruírem de outras regiões da cidade; intervenções capazes se desfazer a sensação de insegurança presente no cotidiano dos idosos, principalmente na região do São Gonçalo; equipamentos que possibilitem a apropriação dos ambientes através da execução de atividades estacionárias, principalmente no Fragata e no São Gonçalo; elementos para acessibilidade que aumentem a oferta de locais onde os cadeirantes sintam-se seguros e confortáveis; e estratégias que ampliem a atratividade do espaço urbano ao público feminino.

Entende-se que, ao suprir estas carências e ao preservar os lugares que os idosos identificam como principais Marcos municipais, a Praça Cel Pedro Osório e a Catedral de São Francisco de Paula, Pelotas reforçará o seu papel, de uma forma potencialmente mais abrangente, como uma cidade amiga do idoso.

Conclui-se que os resultados apresentados poderão subsidiar novos estudos acadêmicos das áreas da Gerontologia Ambiental e da Percepção e Legibilidade e, assim, possibilitarão o surgimento de novas reflexões quanto às relações ambiente-comportamento. 


\section{REFERÊNCIAS}

AMARO, L. E. S.; JOHANN, J. R.; MEIRA, P. R. S. O estilo de vida do idoso urbano: o caso de Porto Alegre - RS. Revista Brasileira de Ciências do Envelhecimento Humano. Passo Fundo, v. 4, n. 1, jan./jun. 2007. p. 115-126.

AMOR, T. Percorrendo a (c)idade com idosos: a construção urbana da vulnerabilidade. Revista Cidades, Comunidades e Territórios, 2011.

BENTLEY, l; ALCOCK, A., MURRAIN, P.; MCGLYNN, S.; SMITH, G. Responsive environments. A manual for designers. Oxford: Architectural Press, 2005.

CAVALCANTI, P. B. A humanização de unidades clinicas de hospital-dia: vivência e apropriação pelos usuários. 2011 . 421 f. Tese (Doutorado em Arquitetura) - Faculdade de arquitetura, Universidade Federal do Rio de Janeiro, Rio de Janeiro, 2011.

CUNHA, M. V. P. O.; SALGUEIRO, E. B. S.; MATIAS, E.; COSTA, A. D. L. A relação entre o ambiente e o usuário idoso - o mapa comportamental como instrumento de avaliação. XIV ENTAC - Encontro Nacional de tecnologia do ambiente construído. Anais... Juiz de Fora, out. 2012.

DUPLAY, C. DUPLAY, M. Méthode ilustrée de création architecturale. Paris: Moniteur, 1985. $448 \mathrm{p}$.

DUVAL, M. G. A. S. Legibilidade de layout e apropriação de espaços abertos coletivos. Estudo de caso do conjunto habitacional Terras Altas. $1997.161 \mathrm{p}$. Dissertação (Mestrado em Planejamento Urbano e Regional) - Faculdade de Arquitetura, Universidade Federal do Rio Grande do Sul, Porto Alegre, 1997.

GEHL, J. Cidade para pessoas. Tradução Anita Di Marco. 2. ed. São Paulo: Perspectiva, 2013.

GEHL, J.; SVARRE, B. How to sdudy public life. Tradução de Karen Ann Steenhard. Washinton: IslandPress, 2013.

GONZÁLEZ, D. S.; TOPETE, M. B. C. Espacios públicos atractivos en el envejecimiento activo y saludable. El caso del mercado de Terán, Aguascalientes (México). Revista de Estudios Sociales, Universidad de los Andes, Colômbia, n. 57, jul. 2016. p. 52-67.

GRINOVER, L. A hospitalidade urbana: acessibilidade, legibilidade e identidade. Revista Hospitalidade. São Paulo, v. 3, n. 2, 2006. p. 29-50.

INSTITUTO BRASILEIRO DE GEOGRAFIA E ESTATíSTICA. Contagem Populacional, 2010. Disponível em: <http://www.sidra.ibge.gov.br/bda/popul>. Acesso em: 10 jan. 2017.

LYNCH, K. A Imagem da Cidade. São Paulo: Arte e Comunicação, 1999.

MEDVEDOVSKI, N. S. A vida sem condomínio: configuração e serviços públicos urbanos em conjuntos habitacionais de interesse social. Tese (Doutorado). São Paulo: Faculdade de Arquitetura e Urbanismo da Universidade de São Paulo, 1998.

NETTO, V. M.; KRAFTA, R. C. Segregação dinâmica urbana: modelagem e mensuração. Revista brasileira de estudos urbanos e regionais. Recife, n. 01 , maio/nov. 1999. p. 133-152. 
ORGANIZAÇÃO DAS NAÇÕES UNIDAS. Plano de ação internacional contra o envelhecimento, 2002. Organização das Nações Unidas. Tradução de Arlene Santos. Brasília: Secretaria Especial dos Direitos Humanos, 2002.

ORGANIZAÇÃO MUNDIAL DA SAÚDE. Guia global: cidade amiga do idoso. Genebra, 2008.

PLACE AGE. Disponível em: <http://placeage.org/en/>. Acesso em: fev. 2017.

SATIRO, A. C. Velhices Sustentáveis. Revista LABVERDE. Universidade de São Paulo, São Paulo, n. 8, 2014. Disponível em:

<http://dx.doi.org/10.1 1606/issn.2179-2275.v0i8p109-139>. Acesso em: dez. 2016. 